\begin{tabular}{c|c|c}
\hline \hline & CLIMATE RESEARCH & Published July 4 \\
Vol. 17: 1-18, 2001 & Clim Res & \\
\hline \hline
\end{tabular}

\title{
Climatic effects of land cover change at different carbon dioxide levels
}

\author{
Mei Zhao ${ }^{1, *}$, Andrew J. Pitman ${ }^{1}$, Thomas N. Chase ${ }^{2}$ \\ ${ }^{1}$ Department of Physical Geography, Macquarie University, North Ryde, New South Wales 2109, Australia \\ ${ }^{2}$ CIRES/CSES/Department of Geography, Campus Box 216, University of Colorado, Boulder, Colorado 80309, USA
}

\begin{abstract}
Land cover change (LCC) simulations were performed at 3 different carbon dioxide levels $(280,355$ and 430 ppmv) using the standard version of the NCAR CCM3 at T42 resolution coupled with the Biosphere-Atmosphere Transfer Scheme (BATS) and a mixed-layer ocean model. We follow the evolution of the initial temperature perturbation within the horizontal and vertical structure of the atmosphere and then examine the $15 \mathrm{yr}$ average of near-surface air temperature and meridional stream function differences between current and natural land cover at the 3 different $\mathrm{CO}_{2}$ levels. Results show that LCC caused temperature perturbations which initially affected only those regions where the land cover was modified. After a short period, however, the effects of LCC propagated to remote regions. While the remote effects of LCC were generally different at each $\mathrm{CO}_{2}$ level, 4 common remote regions of sensitivity were identified in these simulations (North Pacific, North America, northeast Asia and the Indian Ocean). The main factor in explaining the differing remote responses was the change in the zonally averaged background circulation resulting from circulation changes caused by $\mathrm{LCC}, \mathrm{CO}_{2}$ level, and the interaction between these 2 forcings. The $15 \mathrm{yr}$ average seasonal results indicate that LCC may have impacts on surface air temperature which vary in sign between seasons, depending on the character of the initial land cover perturbation as well as local meteorological conditions. We find no evidence that the impacts of $\mathrm{LCC}$ decrease with increasing $\mathrm{CO}_{2}$, rather we show that LCC does appear to affect regional climate at a statistically significant level.
\end{abstract}

KEY WORDS: Land cover change $\cdot \mathrm{CO}_{2}$ level $\cdot$ Surface air temperature $\cdot$ Meridional circulation . Initial perturbation propagation

\section{INTRODUCTION}

The Earth's climate is a significant factor in explaining the patterns of global land cover; on the other hand, land cover has also been shown to affect climate through the exchange of heat, mass and momentum fluxes. Modifications to these fluxes may lead to changes to the regional and global climate; one way through which modifications may occur is via activity that changes the physical characteristics of the surface. Under natural conditions, land cover change (LCC) usually proceeds slowly, but human activities have caused rapid modification in more recent times (Hunt-

*E-mail: mzhao@penman.es.mq.edu.au ley \& Webb 1988). Thomas et al. (1956), Turner et al. (1990), Meyers et al. (1994) and Vitousek et al. (1997) have investigated the role of human activity in modifying land cover at regional to global scales over the past 300 yr. As the impact of human activity on land cover increases, the study of the impact of LCC on the regional and global climate has also increased (Polcher \& Laval 1994, Dirmeyer \& Shukla 1996, Zhang et al. 1996, Xue 1997, Nicholson et al. 1998, Betts 1999, Brovkin et al. 1999). Understanding the mechanisms that link changes in land cover with climate can aid in the understanding, modeling and prediction of global climate change.

In a series of recent papers (Chase et al. 1996, 2000, Pitman \& Zhao 2000, Zhao et al. 2001), the impact of historical LCC impacts on the Earth's climate was 
investigated. Chase et al. $(1996,2000)$ used the NCAR Community Climate Model (CCM2) with fixed seasurface temperatures to simulate the impacts of historical leaf area index (LAI) and LCC on the regional and global climate. They found significant global temperature and precipitation changes which were associated with changes in global-scale circulations when the patterns of observed LAI and LCC were imposed. Zhao et al. (2001) and Pitman \& Zhao (2000) used the NCAR CCM3 coupled with a mixed-layer ocean model to simulate the impact of historical LCC on the global atmospheric circulation and the relative impact of historical LCC and historical $\mathrm{CO}_{2}$ changes. Although Zhao et al. (2001) and Pitman \& Zhao (2000) used a different version of the CCM and a different pattern of LCC, they also found that LCC can impact the global atmospheric circulation. In the global average, they found that the impact of LCC on near-surface air temperature was negligible compared to $\mathrm{CO}_{2}$ impacts. A negligible impact on the global average temperature resulting from LCC was also found by Betts (1999), while Brovkin et al. (1999) found evidence of global cooling since about 1400 due to deforestation. However, at high latitudes and at regional scales, LCC was shown to have an impact on temperature of a magnitude similar to the observed $\mathrm{CO}_{2}$ increase (Pitman \& Zhao 2000). Brovkin et al. (1999) found that the biogeophysical effects of deforestation caused global scale changes of similar magnitude, but of opposite sign, to the warming caused by increasing $\mathrm{CO}_{2}$. Chase et al. (2001) compared temperature results from several GCMs which investigated $\mathrm{CO}_{2}$ or $\mathrm{CO}_{2}$ /aerosol forcing with simulations which examined the impact of historical LCC. They showed that the direct or remote effects of LCC were comparable to the effects of increasing $\mathrm{CO}_{2}$, having a similar amplitude and occurring in the same regions of the globe.

Overall then, the impact of LCC on the global and regional climate remains uncertain. The aim of this paper is to investigate the impact of historical LCC on global climates and how those effects are modified by increasing levels of $\mathrm{CO}_{2}$. Therefore, in contrast to earlier papers, we focus on the impact of LCC at 3 different levels of atmospheric $\mathrm{CO}_{2}$ representing pre-industrial, present-day and future concentrations (280, 355 and $430 \mathrm{ppmv}$, respectively). We also test the significance of these results with greater rigor than has been done in the past. Our aim is to determine whether the impact of LCC is independent of $\mathrm{CO}_{2}$ concentration (i.e. will the influence of LCC on regional and global climate alter as $\mathrm{CO}_{2}$ increases further). In explaining the changes in the impact of LCC at different levels of $\mathrm{CO}_{2}$, we will also focus on some of the mechanisms through which LCC impacts on the regional and global climate. In Section 2 we briefly outline the experimen- tal design and statistical methods. In Section 3, we show the evolution of the initial temperature perturbation of LCC and $15 \mathrm{yr}$ average results with statistical significance tests. Discussion and conclusions are presented in Sections 4 and 5.

\section{EXPERIMENTAL DESIGN AND STATISTICAL METHODS}

We used the standard version of the NCAR CCM3 (Kiehl et al. 1996) at T42 resolution (approximately $2.8^{\circ}$ $\times 2.8^{\circ}$ ) coupled with the Biosphere-Atmosphere Transfer Scheme (BATS, Dickinson et al. 1993) and a mixedlayer ocean model. We performed 3 sets of 2 equilibrium simulations, one using an estimate of natural land cover and the other using current land cover, both at the 280 ppmv $\mathrm{CO}_{2}$ level. Identical pairs of experiments at 355 and 430 ppmv were also performed. Our initial aim was to compare the impact of the change in $\mathrm{CO}_{2}$ from natural (280 ppmv) to current (355 ppmv) with the impact of LCC from natural to current. However, to investigate the role of $\mathrm{CO}_{2}$ increases into the future, we performed an extra simulation with a further 75 ppmv increment (i.e. 430 ppmv). Each simulation was integrated for $17 \mathrm{yr}$. The $\mathrm{CO}_{2}$ change only affects radiation, and no direct $\mathrm{CO}_{2}$ effect on plants was included. The natural land cover data set was obtained from BIOME3 (Haxeltine \& Prentice 1996) and was aggregated from $0.5^{\circ} \times 0.5^{\circ}$ to $\mathrm{T} 42$ resolution. To determine the current land cover data set, we modified the natural land cover predicted by BIOME3 from forest or grass to a crop where LAI changed by more than 1, following Chase et al. (1996). The modified land cover imposed in our experiments leads to a change in a large number of vegetation and soil parameters within BATS. The widespread LCC over South America and Africa imposed by Chase et al. (1996, plate 1) were not included in our experiments, and we also removed some individual points which were geographically isolated. More detail on creating the natural (prior to human activity) and current land cover data can be found in Zhao et al. (2001). Overall, our LCC focussed on 4 main areas: South East Asia (mainly China), India, Europe and USA (Fig. 1), and these changes are largely constrained to $15-60^{\circ} \mathrm{N}$. It is worth noting that, in contrast to a sea-surface temperature anomaly, LCC causes an essentially permanent surface anomaly, although this may vary in sign depending on many factors, including season and local meteorological conditions. In our experiments we changed approximately $7.9 \%$ of the land area, which contrasts with the findings of Vitousek et al. (1997), who suggest that around $45 \%$ of the global land area has been modified by human activity. 
(a)

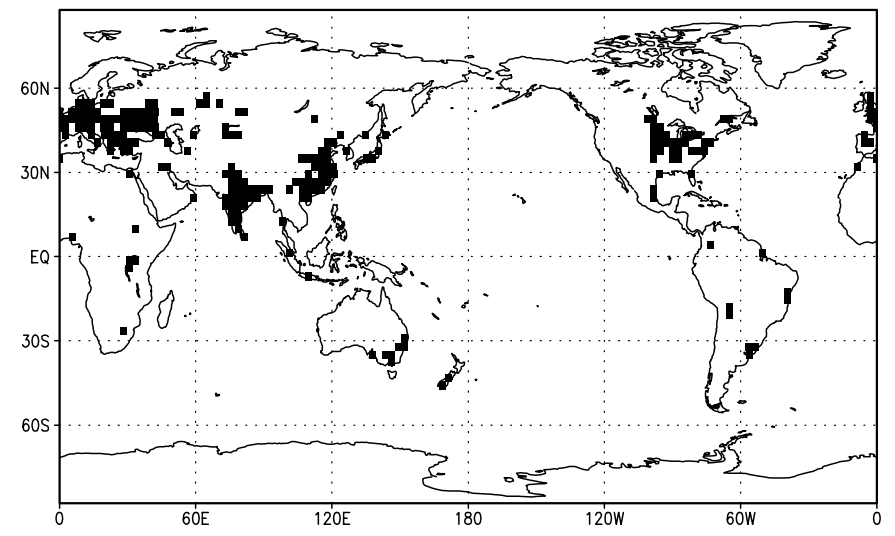

(b)

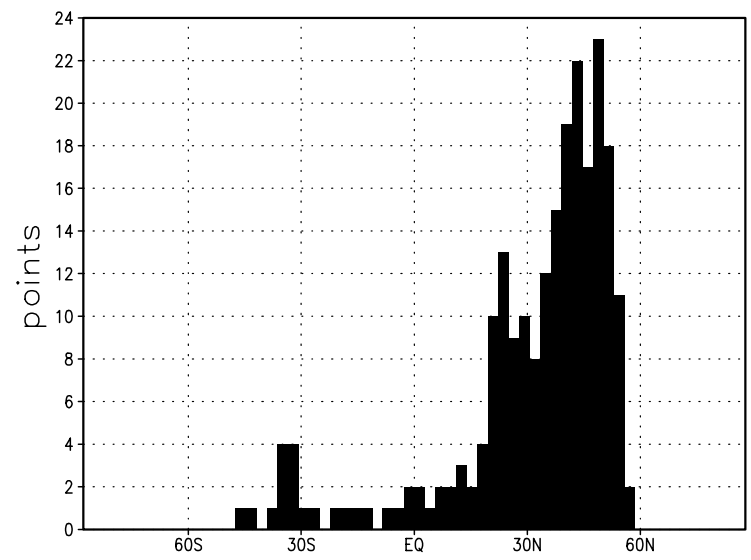

(c)

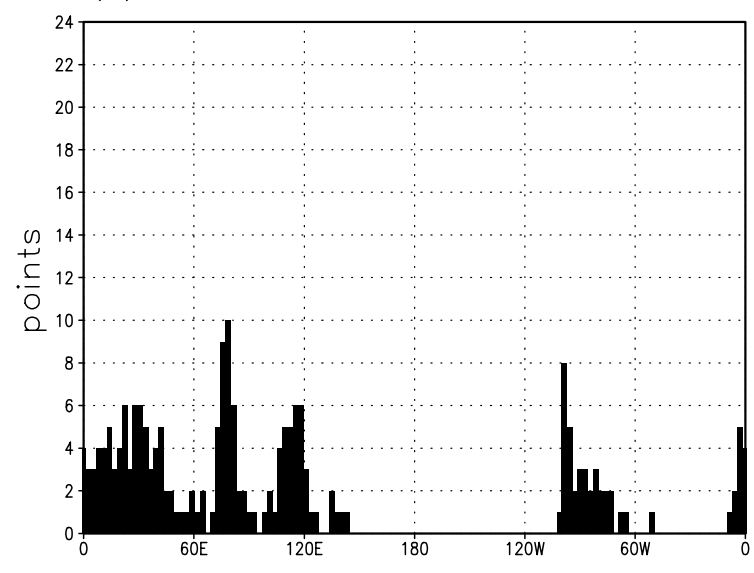

Fig. 1. Land cover change (LCC) between the current and natural scenarios described in the text. (a) Geographical distribution of LCC; (b) number of points changed as a function of latitude; (c) number of points changed as a function of longitude

Spin-up was achieved after about 2 yr. When average results are shown, these are averaged over the last 15 of 17 yr integration. In all cases, results are presented as the current vegetation simulation minus natural vegetation simulation.

To assess the reliability of the simulated impact of LCC on climate change, a statistically significant test is required. All differences were initially tested with Student's $t$-tests to establish significance. However, since climate variables tend to be correlated in space and time, the underlying assumption of independence in the traditional $t$ - and $F$-tests may be violated. Additionally, these tests may not be sufficiently powerful to detect climate changes with the relatively small sample size typical of a LCC experiment (i.e. 10 to $15 \mathrm{yr}$ integration). Therefore, we also applied the $Z$-test proposed by Katz (1982) to the temperature mean field. This procedure is based on parametric time series modeling involving the fitting of low-order autoregressive processes. It has 2 main advantages over the traditional $t$-test. First, it is based on a large number of daily samples rather than limited monthly or seasonal averaged samples. Second, the $Z$-test does not require that the population variance in the control and experiment time series be equal or that the samples be independent. The methodology requires an appropriate model (i.e. the order of autoregressive process) to be identified; Katz (1982) suggests the use of the Bayesian information criterion (BIC) for selecting the appropriate order of the autoregressive process and showed that the maximum order was 5 , but when applied to climate model results, this was concentrated on order 2 and 3 . We calculated the $Z$-test for each order (up to 4 ) and found that for most of the grid points chosen, the second and the third order appeared to be satisfactory. Although applying a second order at all grid points gives the largest total area of significance, the results shown in this paper utilize the BIC procedure which Katz (1982) argues improves the reliability of the methodology. As discussed in Katz (1982), and confirmed by our own experience, the $Z$-tests tend to indicate larger regions of stronger statistical significance 
than the $t$-test because of the use of daily samples. For 3-dimensional fields the daily information required by the $Z$-test could not be stored, and hence differences were tested only with the $t$-test.
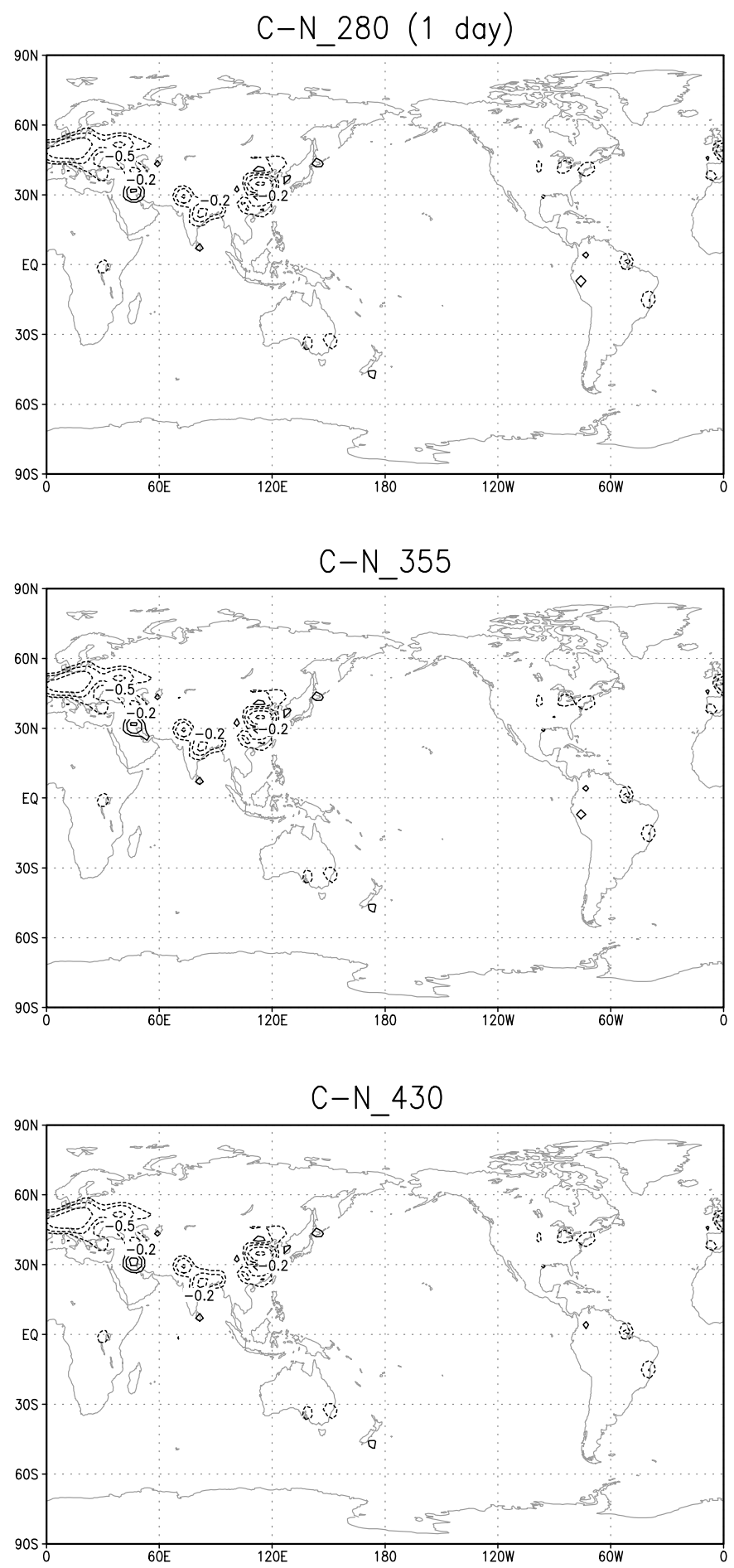

Fig. 2. The initial perturbations of near-surface air temperature caused by LCC (first day of integration) at $3 \mathrm{CO}_{2}$ levels $(280,355$ and 430 ppmv from top to bottom)
As an additional test of the statistical significance of our results, we have also used the 2-way analysis of variance (ANOVA) techniques developed by Zwiers (1996) applied to the temperature variance field. ANOVA is designed for ensemble model runs and can separate signals resulting from different forcing (e.g. LCC compared to changes in $\mathrm{CO}_{2}$ ) as well as separating forcing signals from model variability. We used an ensemble of six $15 \mathrm{yr}$ simulations (2 types of land cover at $3 \mathrm{CO}_{2}$ levels), assuming that the seasonal mean time series is comprised of 4 components: a LCC-forced component, a $\mathrm{CO}_{2}$-forced component, an interaction of LCC and $\mathrm{CO}_{2}$ components and an internal variability (variation between years and runs that is not accounted for by the other 3 terms). This enables separation of the variability due to the forced component (due to $\mathrm{LCC}$ or changes in $\mathrm{CO}_{2}$ ) from that due to the model variability. Since the forced component is not sensitive to initial conditions (Zheng et al. 2000), it becomes potentially predictable. Details regarding this method can be found in Appendix 1.

\section{RESULTS}

\subsection{Evolution of the initial perturbation of LCC}

On the first day of integration (the model is initialized 1 September), the initial perturbation patterns in near-surface air temperature (Fig. 2) are isolated to locations of LCC (Fig. 1). The differences in the air temperature over Europe, India and China exceed $-1.0 \mathrm{~K}$ at all $3 \mathrm{CO}_{2}$ levels. Over the USA, the impact of LCC on air temperature is less than $-0.3 \mathrm{~K}$. The close association of temperature change with location of LCC indicates that LCC does perturb the atmosphere locally. It will be shown later that these local perturbations propagate horizontally and vertically through the atmosphere. Fig. 2 also shows that the initial perturbation in the air temperature varies in sign between regions. This results from different changes in the parameter values used within BATS in different locations (the vegetation types vary in the natural case, and since all these are changed to crop, the net changes in parameters vary) and from variations in meteorological conditions locally. It is noteworthy that the differences between the air temperatures simulated on Day 1 between the $3 \mathrm{CO}_{2}$ levels are negligible, indicating the initial (Day 1) difference due to LCC is not related to $\mathrm{CO}_{2}$ level.

Figs. $3 \& 4$ present the 10 th and 30th day integration results respectively for near-surface air temperature. In Fig. 3, the initial perturbation has propagated across the Eurasian continent and a temperature difference of $2 \mathrm{~K}$ is quite common at all $3 \mathrm{CO}_{2}$ levels. A change in air 
temperature is also visible over the USA as well as in some high-latitude areas. The patterns of change in air temperature remain very similar at the $3 \mathrm{CO}_{2}$ levels. After 30 days (Fig. 4), the impact of LCC has extended to the global scale. Large differences are visible at high latitudes in both hemispheres, remote from regions of LCC. However, these changes are also related to the large natural variability in these regions, and it
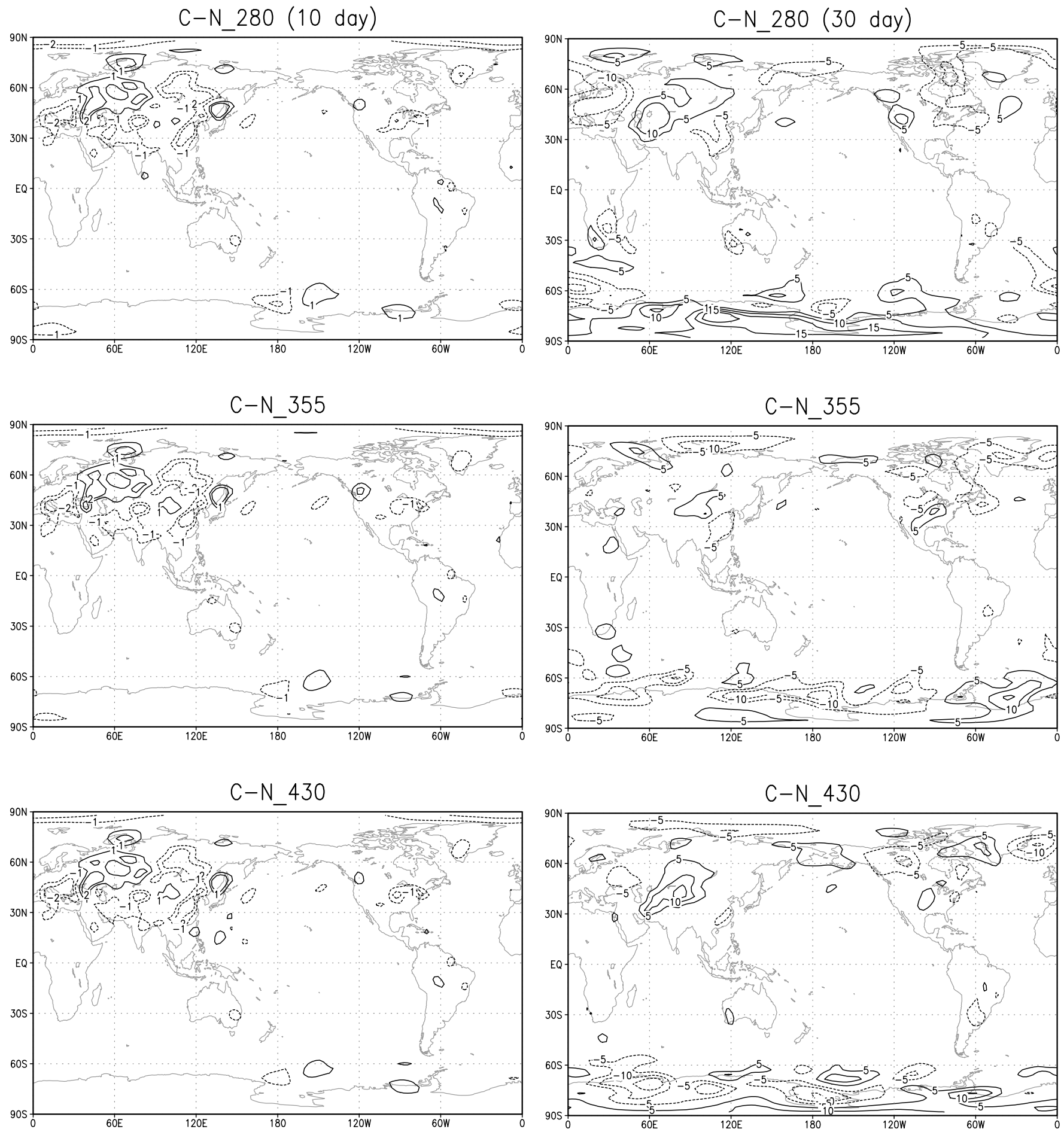

Fig. 3. The initial perturbations of near-surface air temperature caused by LCC (10th day of integration) at $3 \mathrm{CO}_{2}$ levels $(280$, 355 and $430 \mathrm{ppmv}$ from top to bottom)

Fig. 4. The initial perturbations of near-surface air temperature caused by LCC (30th day of integration) at $3 \mathrm{CO}_{2}$ levels (280, 355 and 430 ppmv from top to bottom) 

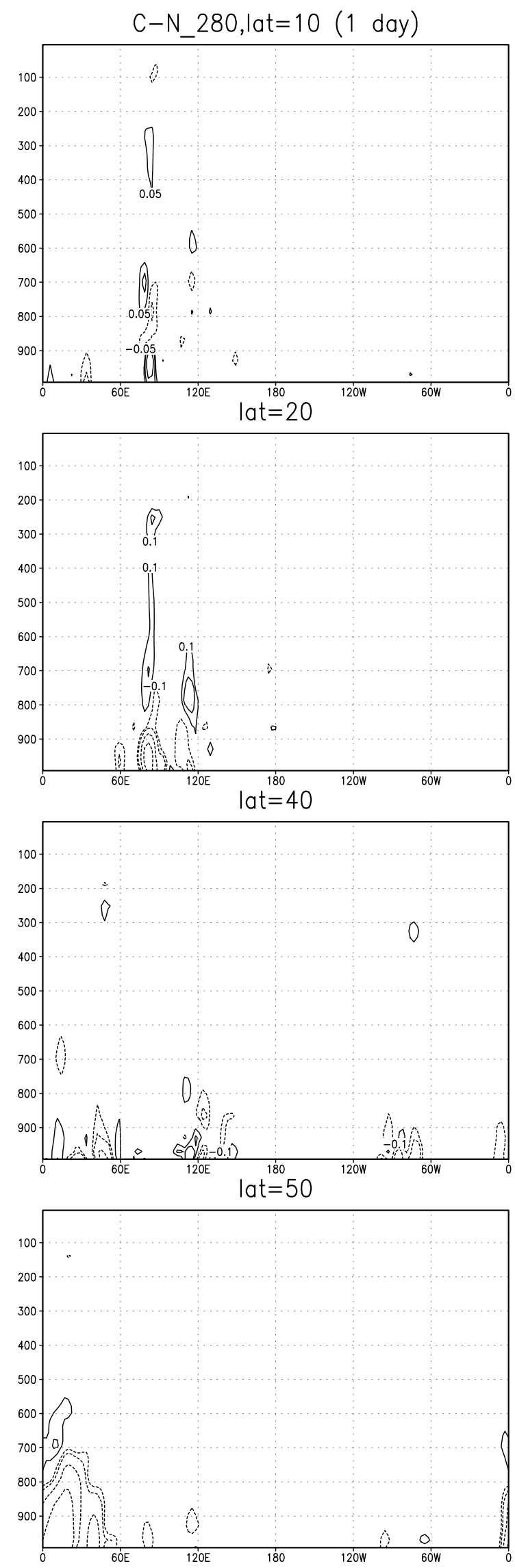

becomes increasingly difficult to attribute differences directly to LCC. By Day 30, the patterns of temperature differences caused by LCC are partially dependent on the background circulation which has, by this point, been affected both by changes in $\mathrm{CO}_{2}, \mathrm{LCC}$ and the interaction of the two. Similarities between the simulations remain apparent over the location of the LCC as well as over central Eurasia (positive).

The changes in temperature shown in Figs. 2 to 4 remote from the location of LCC result from the propagation of the initial perturbation through the atmosphere. This can be seen clearly by viewing the changes in the vertical temperature structure of the atmosphere for $\mathrm{CO}_{2}$ at 280 ppmv. On Day 1 (Fig. 5) the initial perturbation of low-level temperatures can be seen in those regions where LCC was imposed. The differences in vertical structure between the simulations at the 3 levels of $\mathrm{CO}_{2}$ on Day 1 are negligible (figure not shown). The initial atmospheric perturbation in the mid-latitudes is larger than in the tropics.

Figs. $6 \& 7$ show the evolution of the vertical structure of temperature perturbation (5th day at $280 \mathrm{ppmv}$ and 30th day integration at $3 \mathrm{CO}_{2}$ levels, respectively). Although the local largest perturbation is still in the low levels of the atmosphere after 5 days (Fig. 6), higher levels are also clearly affected. After 5 days, the patterns are still similar for the $3 \mathrm{CO}_{2}$ levels (not shown). The magnitude of the changes shown in Fig. 6 are much larger over the mid-latitudes than in the tropics. This may be related to the higher overall variability in the mid-latitudes or the geographical extent of the LCC. The vertical structure of temperature on the 30th day of integration (Fig. 7) are quite different at the $3 \mathrm{CO}_{2}$ levels, indicating the increasing effect of the interaction between $\mathrm{CO}_{2}$ and LCC effects as well as inherent model variability. Despite these differences, it is still clear that the longitudinal locations of the maximum positive and negative centers remain similar, especially in the mid-latitudes.

Overall, it is clear that from the initial perturbation changes develop and propagate through time vertically and horizontally. The location and initial development of the change is tightly coupled to the location of LCC and not to model variability or $\mathrm{CO}_{2}$ concentration. However, as the integration continues, the local perturbations propagate horizontally and vertically through the atmosphere such that the monthly averaged pattern of changes do depend on the $\mathrm{LCC}, \mathrm{CO}_{2}$ concentration changes and the interaction between the two. This is discussed in more detail in the following section.

Fig. 5. Vertical structure of initial perturbation of near-surface air temperature (first day of integration) caused by LCC at 280 ppmv $\mathrm{CO}_{2}$ level, latitude is $10,20,40$ and $50^{\circ} \mathrm{N}$ (top to bottom) 


\subsection{Fifteen year average results with statistical tests}

Fig. 8 shows the 15 yr average near-surface air temperature differences between the current and natural land cover at $3 \mathrm{CO}_{2}$ levels in 4 seasons (DJF, MAM, JJA and SON). The $90 \%$ significance level calculated using a 2-tailed $Z$-test is shaded. At all $3 \mathrm{CO}_{2}$ levels, large responses to the LCC change can be seen particularly in the local areas where the initial perturbation in LCC occurs. Statistically significant impacts in the mid- and high latitudes over the land and over the North Pacific, North America, northeast Asia and Indian Ocean are also common. In locations directly affected by LCC, the temperature changes are quite similar at the 3 different $\mathrm{CO}_{2}$ levels, while in areas remote from $\mathrm{LCC}$, the pattern and size in the temperature changes are quite different at the 3 different levels. The similarity of the initial LCC response for each of the $\mathrm{CO}_{2}$ levels is an indication that the differences in remote effects are, for the most part, the result of changes in the background circulation caused by the interactions between the LCC effects and $\mathrm{CO}_{2}$ level.

At the seasonal time-scale, statistically significant LCC impacts can be seen in India and south China in all 4 seasons and at the $3 \mathrm{CO}_{2}$ levels (Fig. 8). In contrast, Europe has large negative impacts in JJA and some positive impacts in SON (also statistically significant). Over the USA, it is hard to find a common signal at different $\mathrm{CO}_{2}$ levels, possibly because the initial perturbation is relatively small, but also because the propagation of the initial perturbation extends over the ocean rather than over the land, in contrast to Europe. LCC impact in the Indian region is negative in all 4 seasons. In China, LCC caused negative changes in DJF, but positive changes in other seasons. Clearly, LCC has different impacts in different locations and in different seasons.

Table 1 shows the percentage of the globe where statistically significant changes in the near-surface air temperature were found (calculated using a 2-tailed $Z$ test with 80, 90 and 95\% significance levels). In DJF, LCC at 355 ppmv has the largest percentage of the globe affected by significant changes. In the other seasons, the percentage area of statistically significant change increases with $\mathrm{CO}_{2}$, particularly in JJA. Compared to the $t$-test, the $Z$-test shows larger regions of statistical significance, which is attributable to using a large number of daily samples (see Appendix 1). The reduced area of statistically significant change found at high latitudes in the Z-test is an indication that this

Fig. 6. Vertical structure of initial perturbation of near-surface air temperature (5th day of integration) caused by LCC at 280 ppmv $\mathrm{CO}_{2}$ level, latitude is $10,20,40$ and $50^{\circ} \mathrm{N}$ (top to bottom)
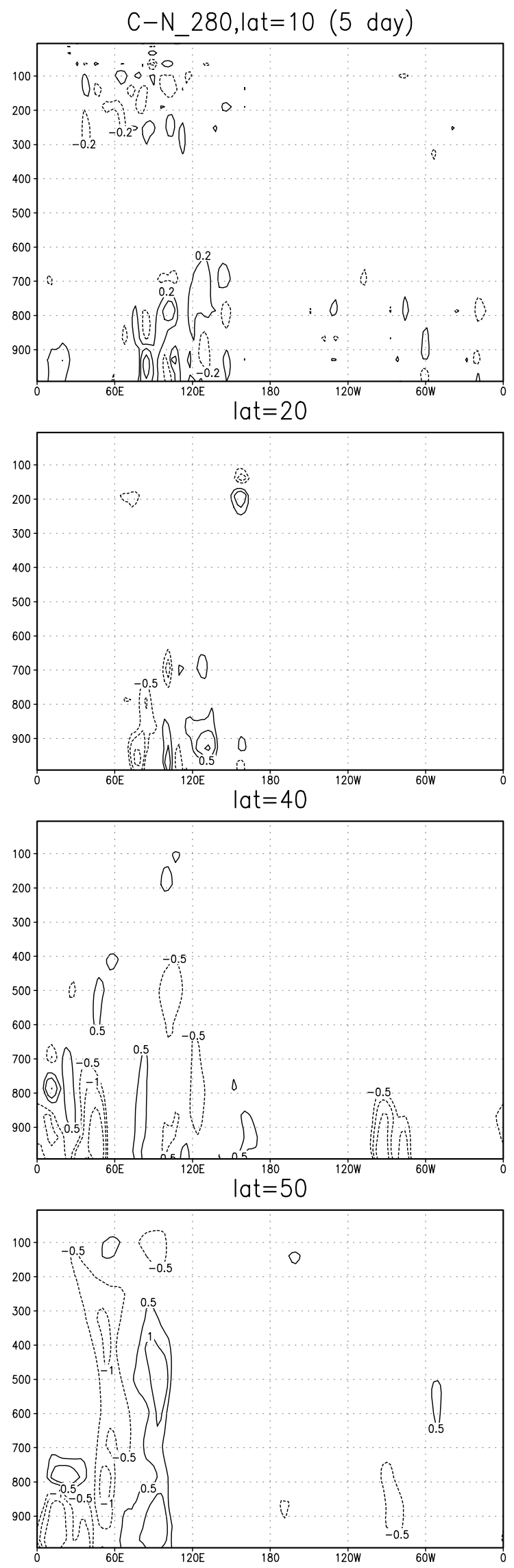
Table 1. Percentage of global area showing statistically significant change in the 4 seasons at the 80,90 and $95 \%$ significance levels using a 2 -tailed $Z$-test

\begin{tabular}{|cccccr|}
\hline & & DJF & MAM & JJA & SON \\
\hline 280 ppmv & $80 \%$ & 30 & 20 & 20 & 19 \\
& $90 \%$ & 20 & 11 & 13 & 10 \\
& $95 \%$ & 13 & 6 & 9 & 6 \\
355 ppmv & $80 \%$ & 36 & 22 & 29 & 23 \\
& $90 \%$ & 24 & 11 & 19 & 13 \\
& $95 \%$ & 17 & 7 & 13 & 7 \\
430 ppmv & $80 \%$ & 32 & 25 & 36 & 28 \\
& $90 \%$ & 21 & 15 & 25 & 16 \\
& $95 \%$ & 15 & 10 & 18 & 10 \\
\hline
\end{tabular}

test is more able to separate signal from noise in regions of high climate variability. However, the overall regional pattern of the statistically significant areas is similar between the 2 tests ( $t$-tests not show).

Fig. 9 shows the results of the ANOVA method for the changes in near-surface air temperature variance resulting from LCC (see Section 2 and Appendix 1). The shaded areas indicate common regions where all 6 simulations show statistically significant variations in the variance of near-surface air temperature due only to LCC at the $90 \%$ significance level. LCC effects tend to be largest in MAM and JJA, with the geographical extent of statistically significant changes over land rather than over ocean. The North Pacific, North America, northeast Asia and the Indian Ocean are 4 remote areas which have a large and common response to LCC.

We have shown that LCC can have significant effects on regional near-surface air temperatures both locally and in regions remote from actual LCC. LCC also appears to affect the global-scale circulations, which is one mechanism by which LCC can affect remote regions. We now examine these changes in circulation in more depth. Fig. 10 shows the LCC impact on zonally averaged meridional circulation at $3 \mathrm{CO}_{2}$ levels, with shaded regions indicating $80 \%$ significance levels in a 2-tailed $t$-test (the $Z$-test requires daily data, which could not be achieved for 3-dimensional fields).

The changes in the large-scale circulation due to LCC at differing $\mathrm{CO}_{2}$ levels result from interactions between the 2 forcings. This is seen in Fig. 10a, where the Hadley cell is seen to decrease near to the equator and statistically significantly increase between 10 and

Fig. 7. (Adjacent panel and facing page.) Vertical structure of initial perturbation of near-surface air temperature (30th day of integration) caused by LCC at $280 \mathrm{ppmv} \mathrm{CO}_{2}$ level, latitude is $10,20,40$ and $50^{\circ} \mathrm{N}$ (top to bottom). (a) 280, (b) 355 and (c) 430 ppmv $\mathrm{CO}_{2}$ levels
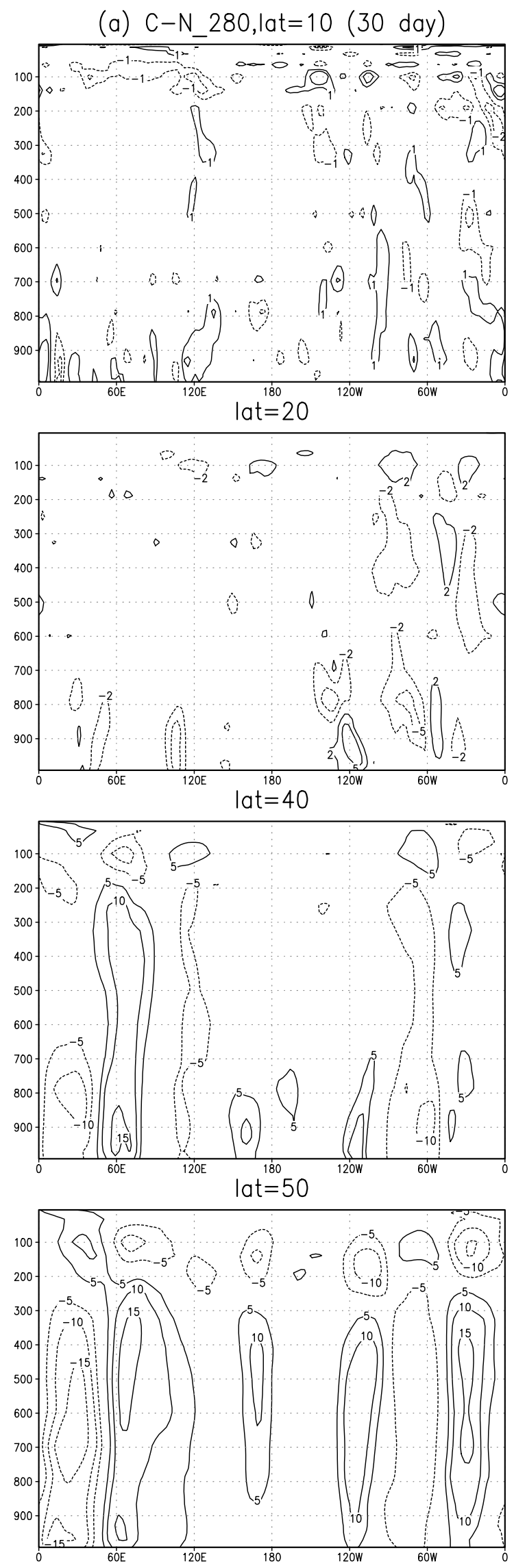
Zhao et al.: Climatic effects of land cover change at different $\mathrm{CO}_{2}$ levels

9

(b) C-N_355,lat=10 (30 day)
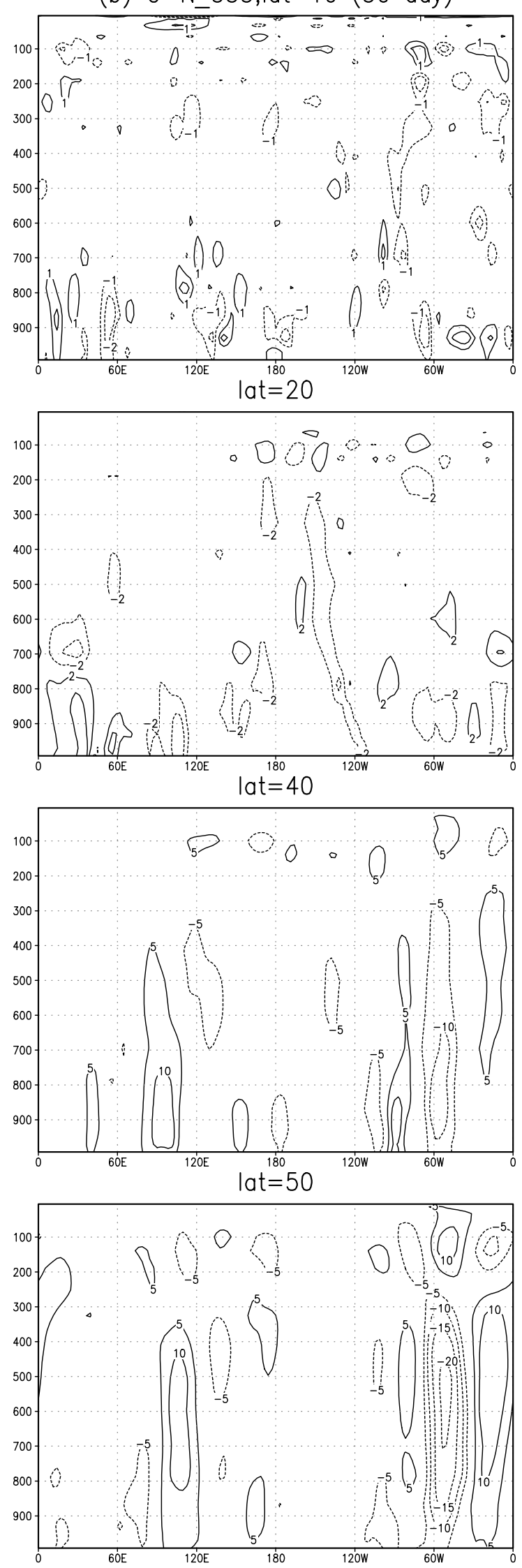

(c) C-N_430, lat $=10$ (30 day)
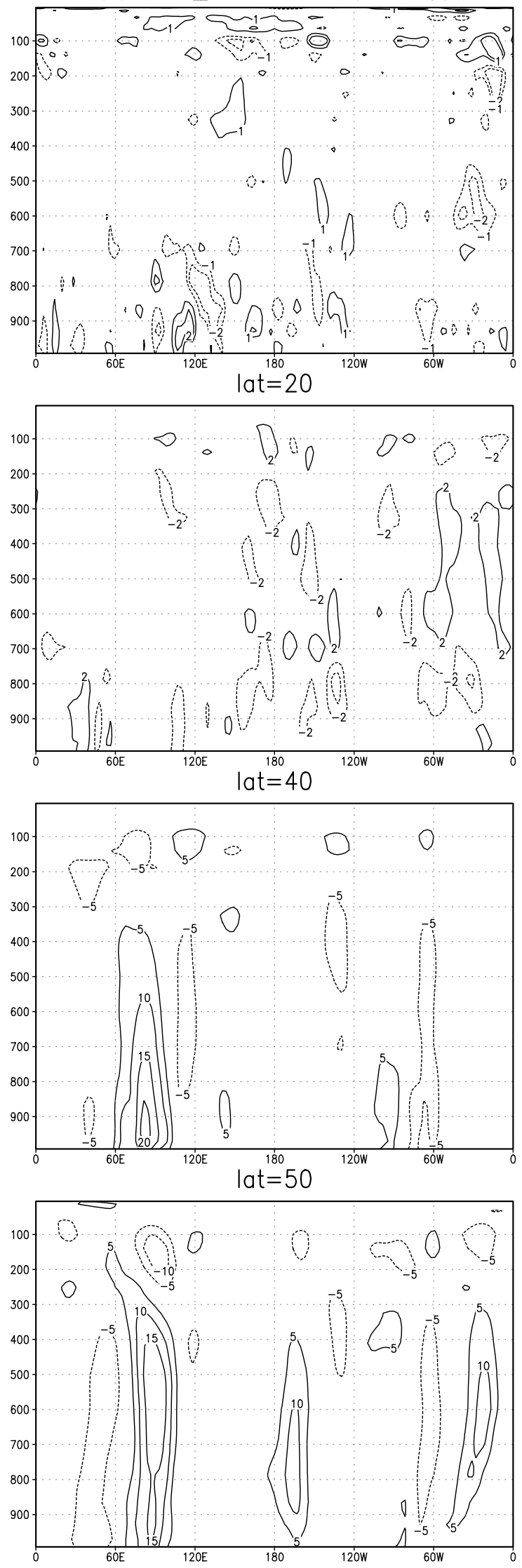
(a) DJF

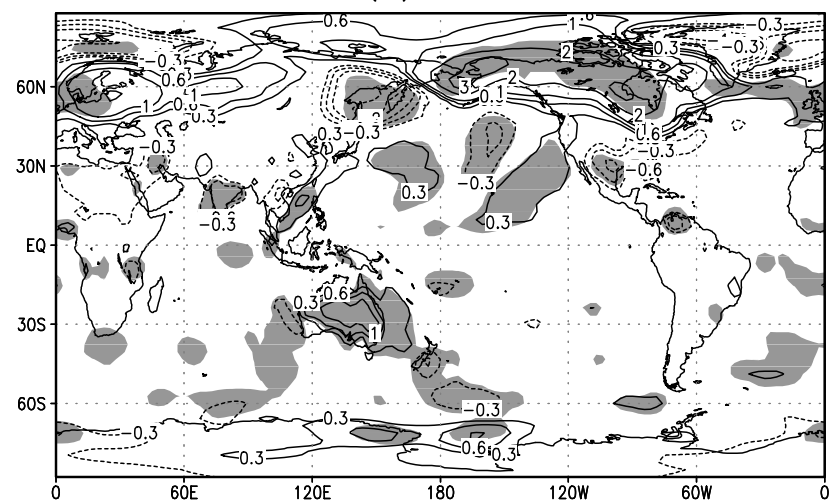

MAM

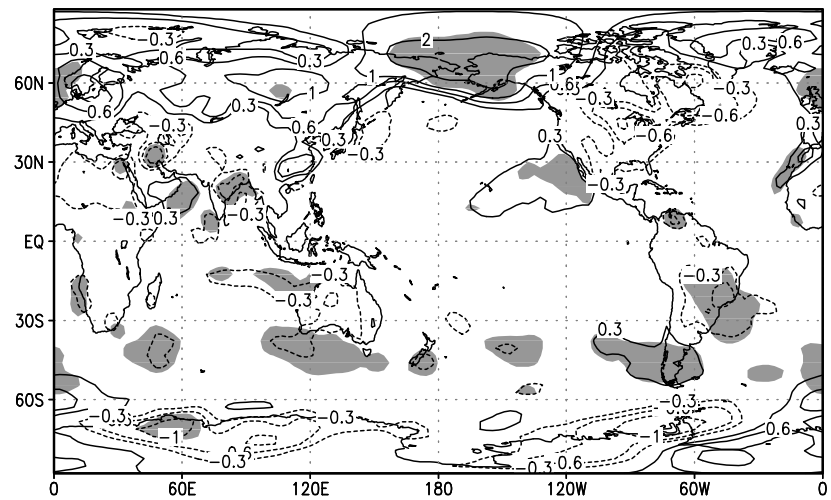

JJA

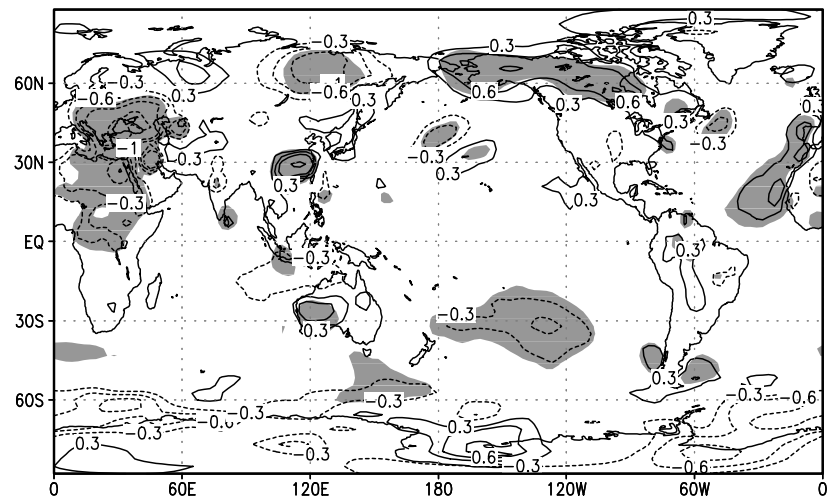

SON

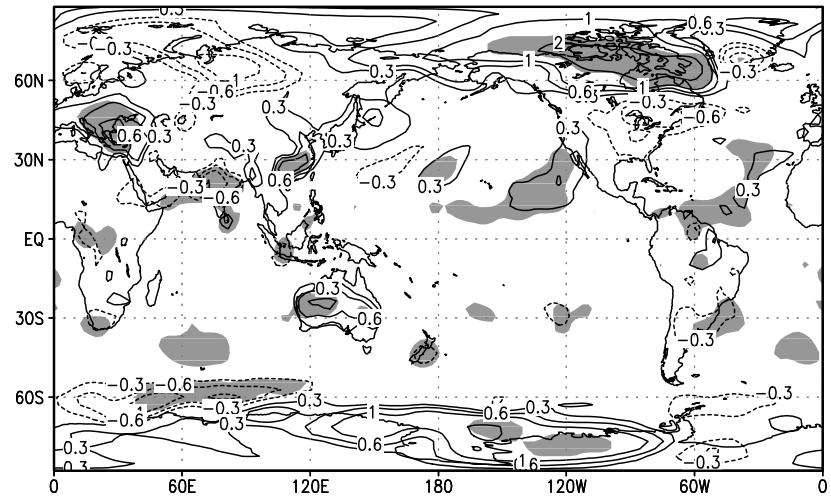

(b) DJF

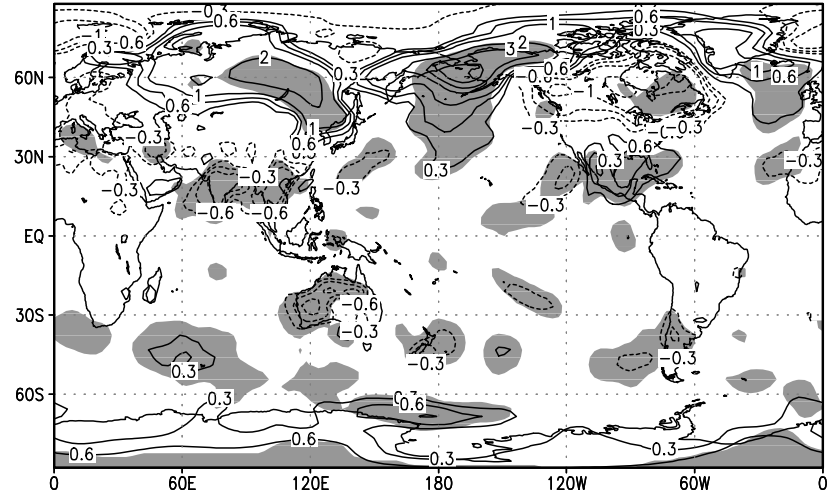

MAM

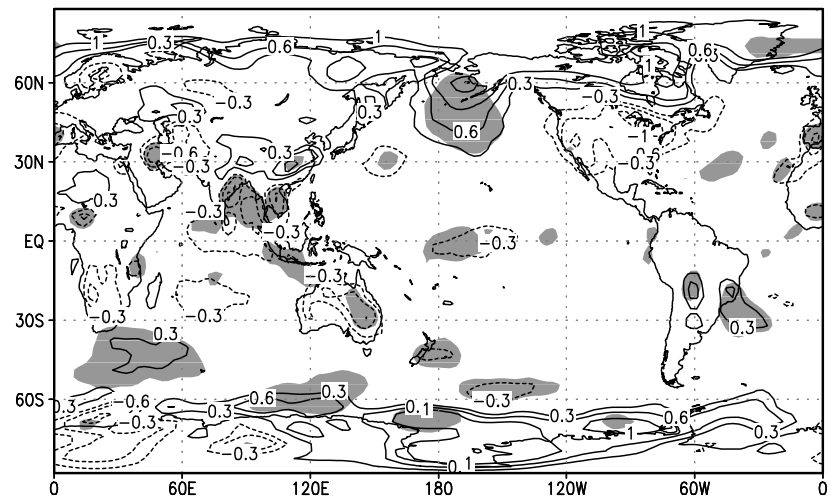

JJA

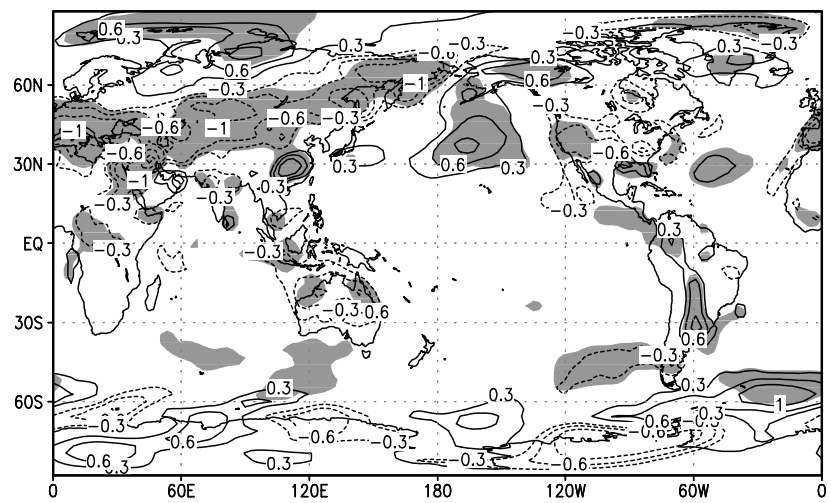

SON

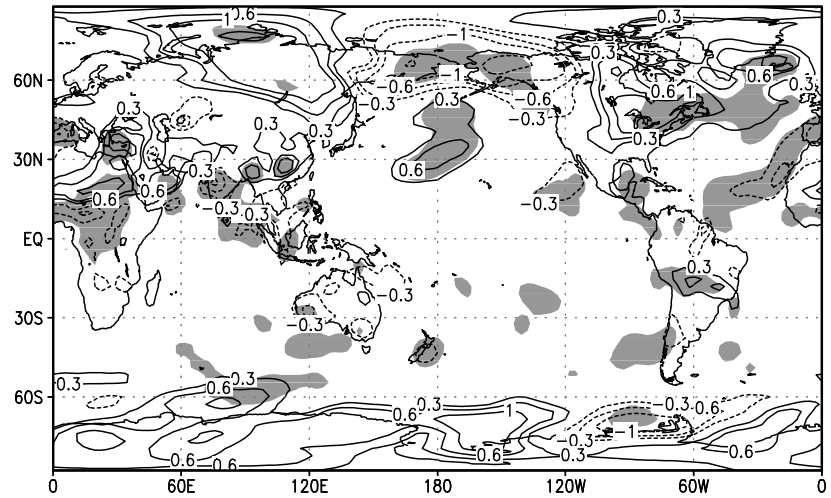

Fig. 8. (Above and facing page.) Current minus natural 15 yr average near-surface air temperature at (a) 280, (b) 355 and (c) 430 ppmv $\mathrm{CO}_{2}$ levels in DJF, MAM, JJA and SON with 2-tailed Z-test at the $90 \%$ significance level (shaded) 
(c) DJF

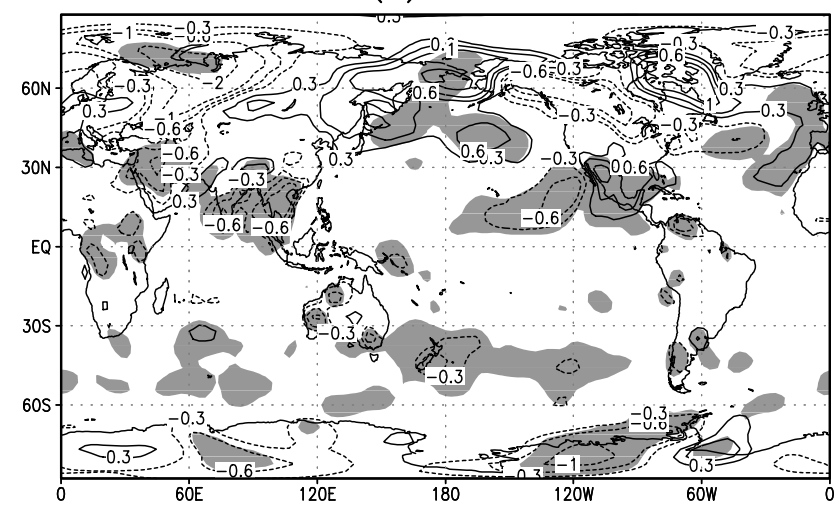

MAM

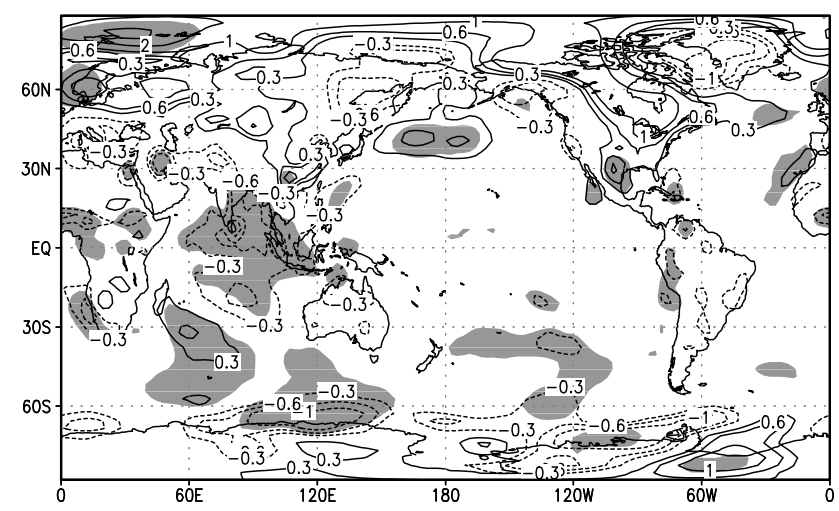

JJA

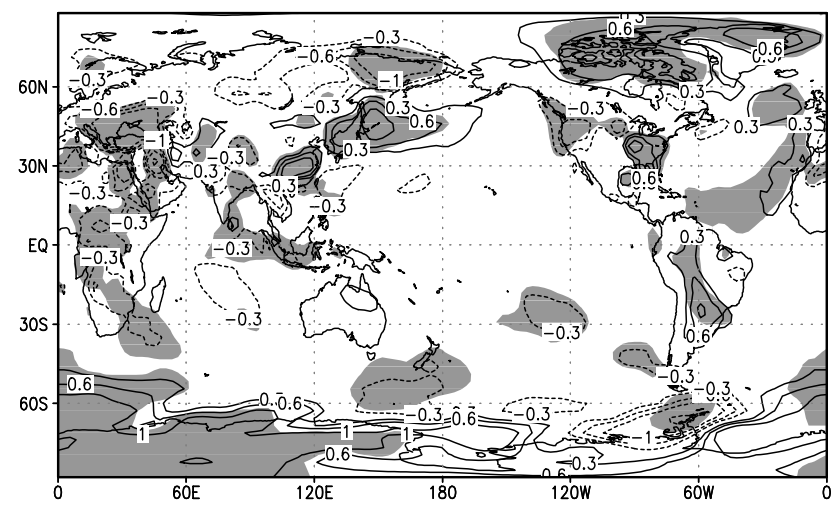

SON

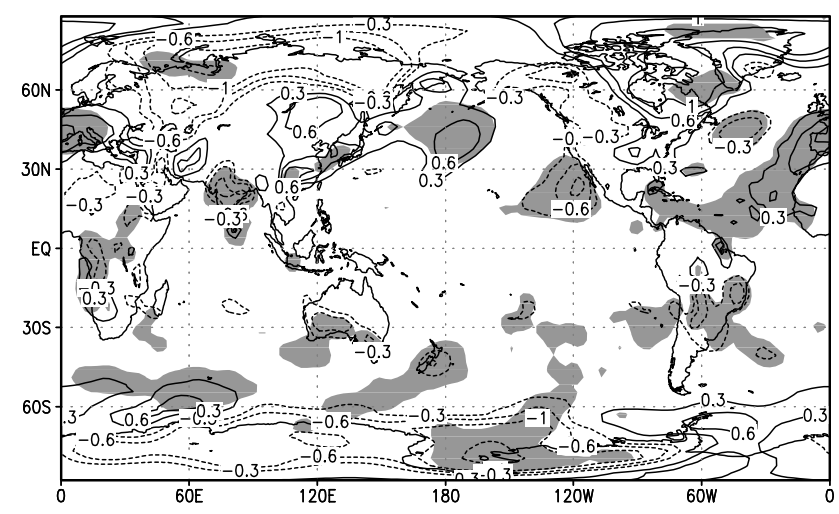

Fig. 8 (continued)
DJF

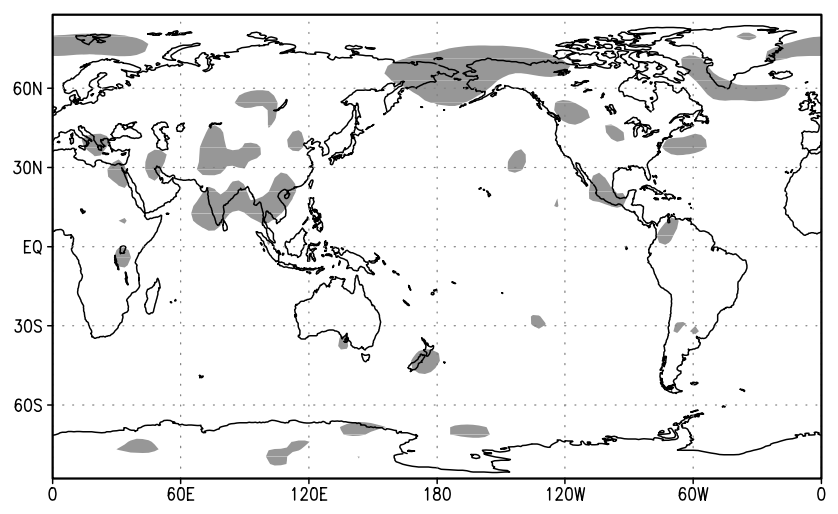

MAM

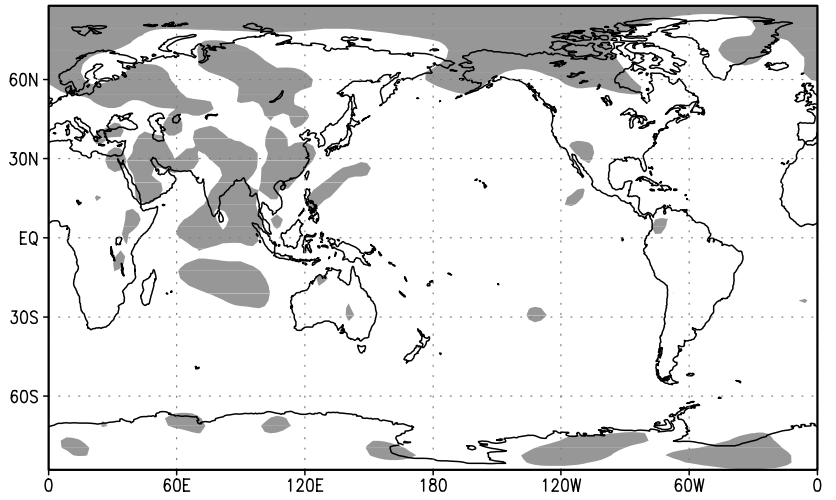

JJA
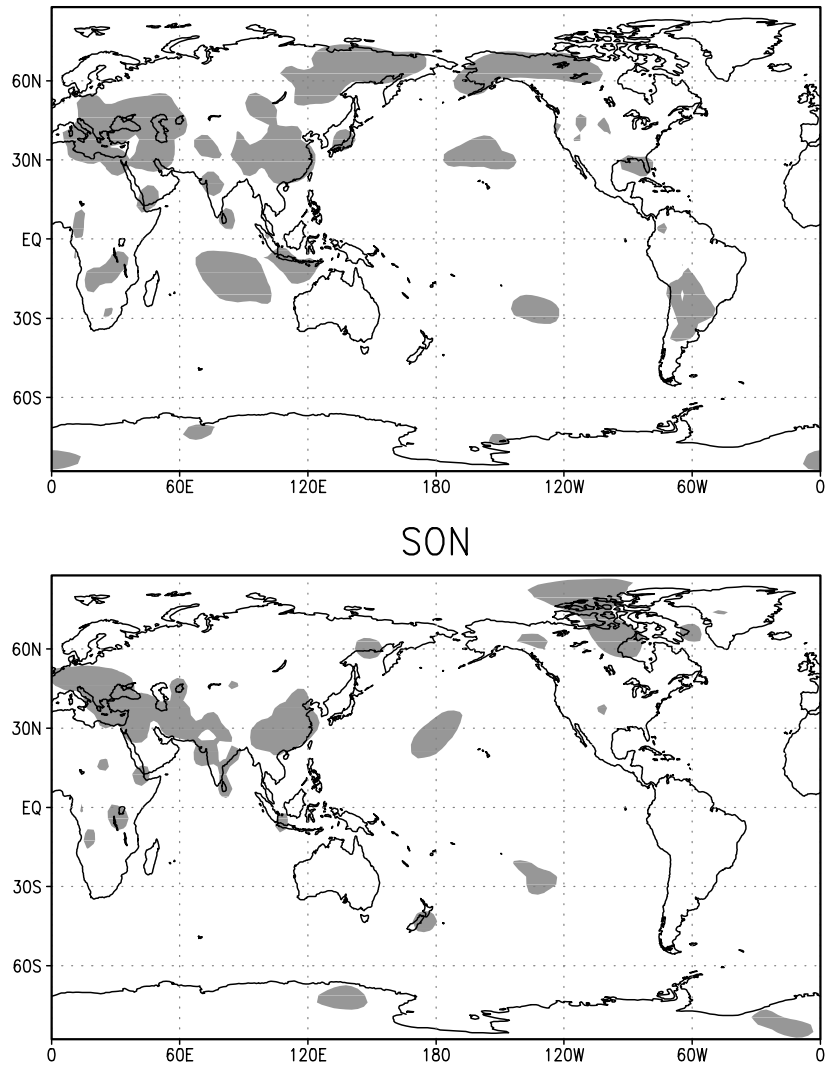

Fig. 9. Regions where LCC causes statistically significant changes in the near-surface air temperature at the $90 \%$ significance level (shaded) in DJF, MAM, JJA and SON; produced using 2-way ANOVA 
(a) $\mathrm{C}-\mathrm{N} 280$
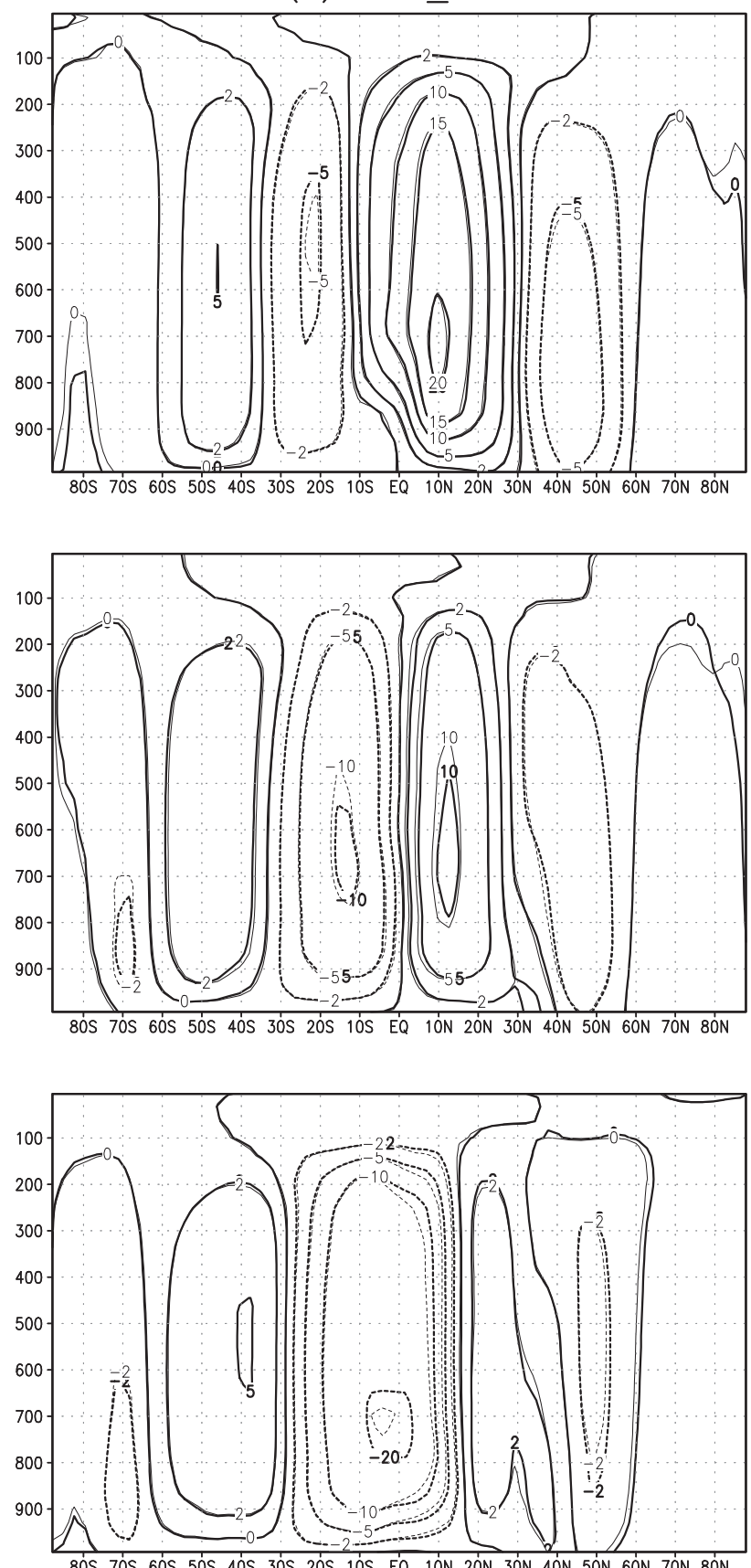

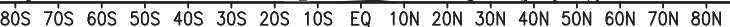

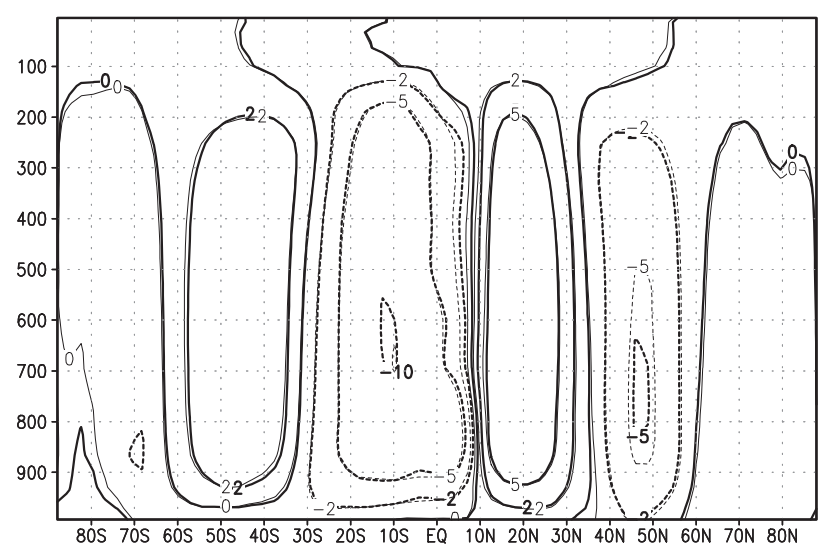

Difference in DJF

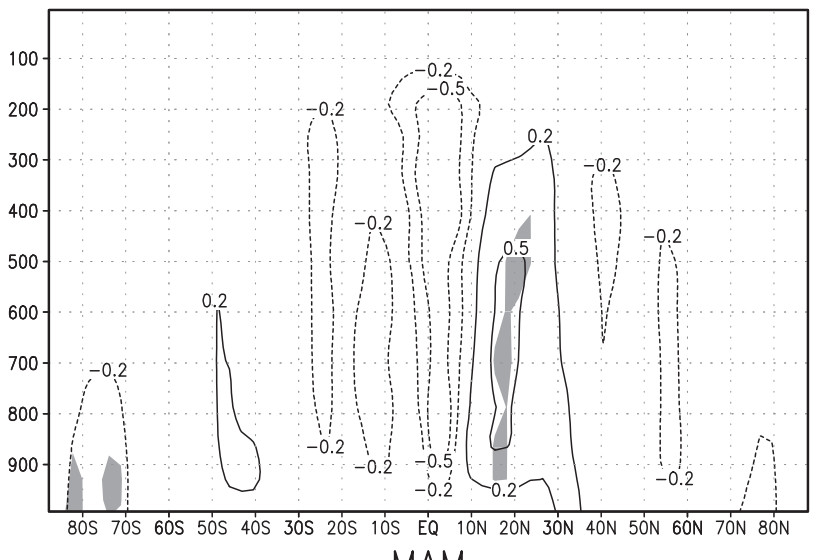

MAM

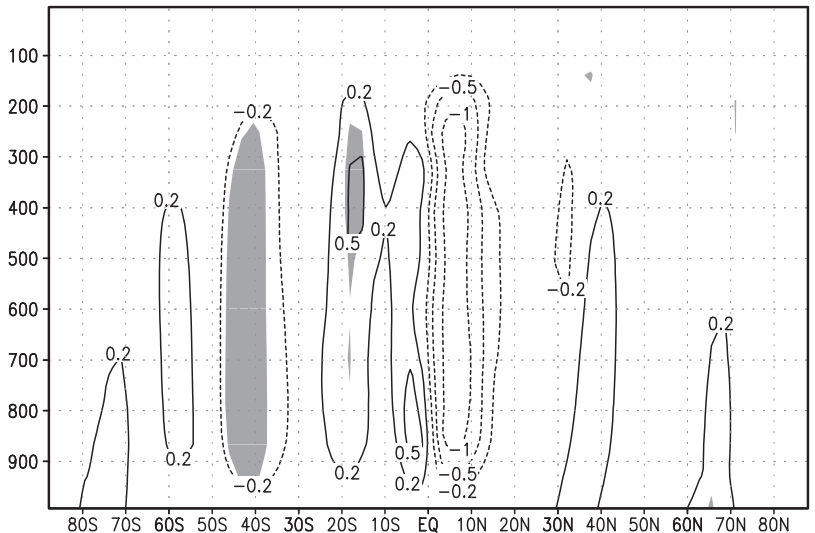

JJA
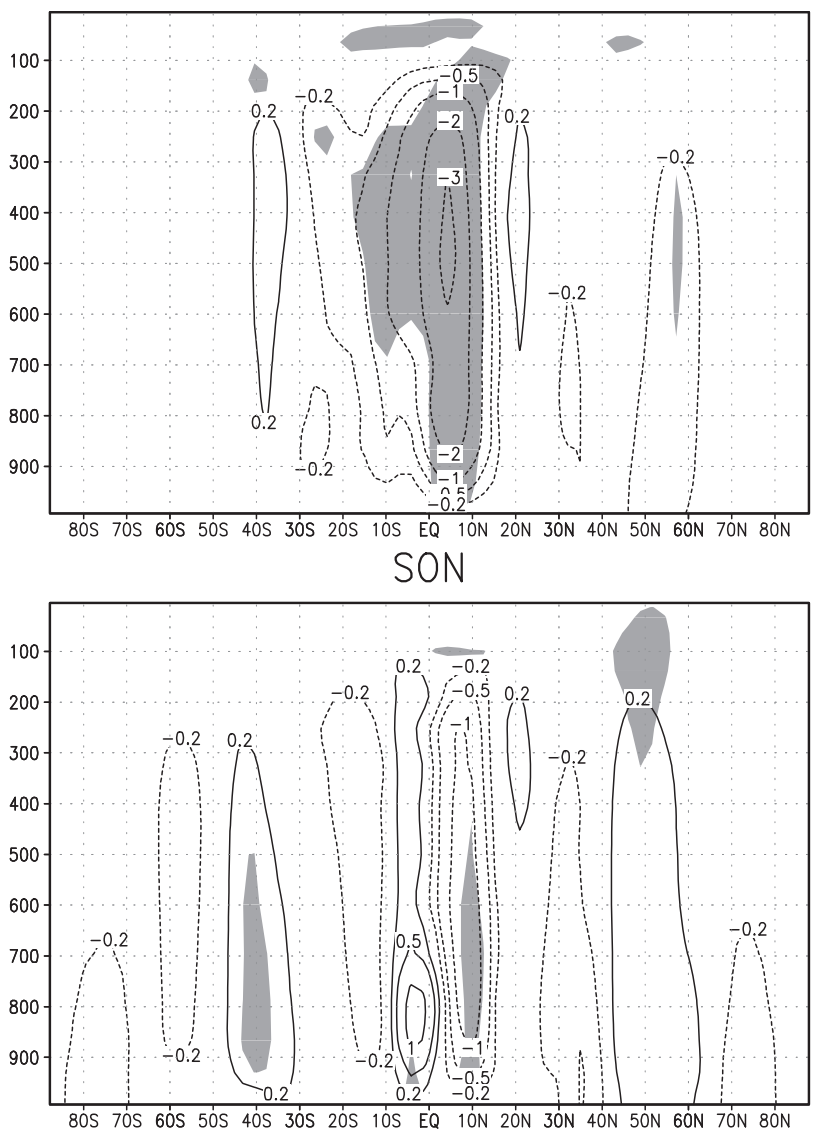

Fig. 10. (Above and following 2 pages.) Fifteen year average meridional stream function (current case is dark, natural case is light) and differences at (a) 280, (b) 355 and (c) 430 ppmv $\mathrm{CO}_{2}$ levels in DJF, MAM, JJA and SON with 2-tailed $t$-test at the $80 \%$ significance level 
(b) $\mathrm{C}-\mathrm{N} \_355$
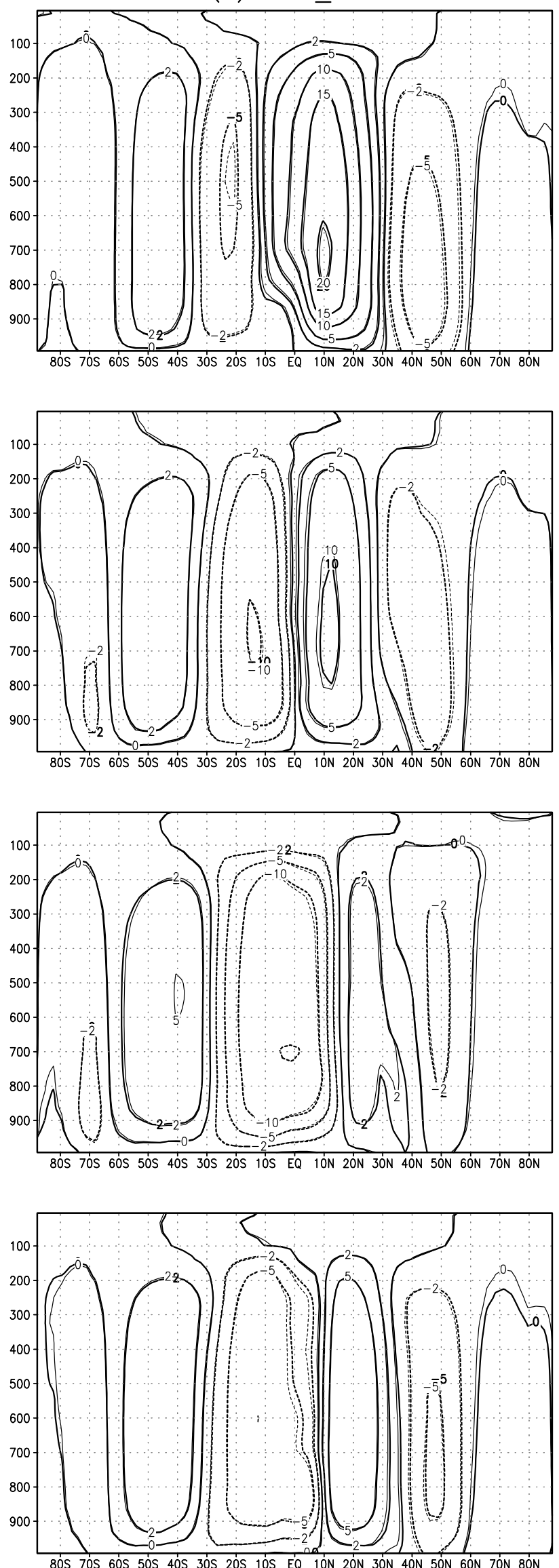

Difference in DJF

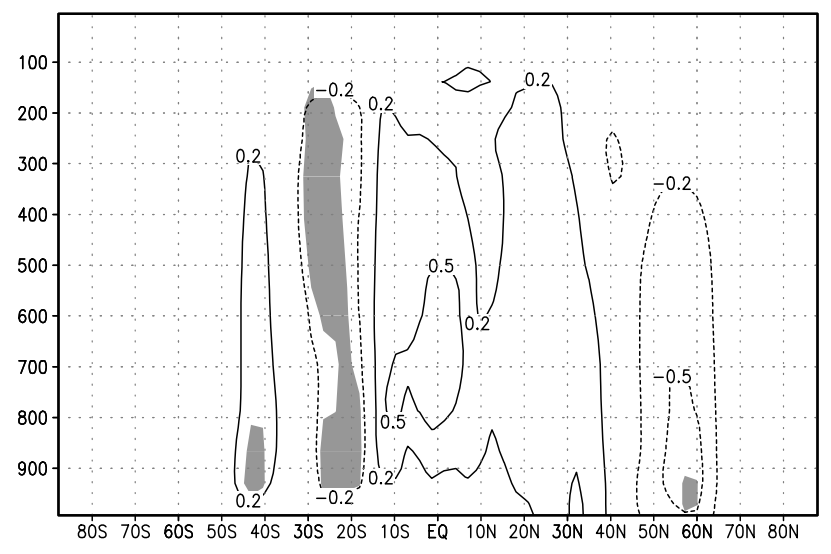

MAM

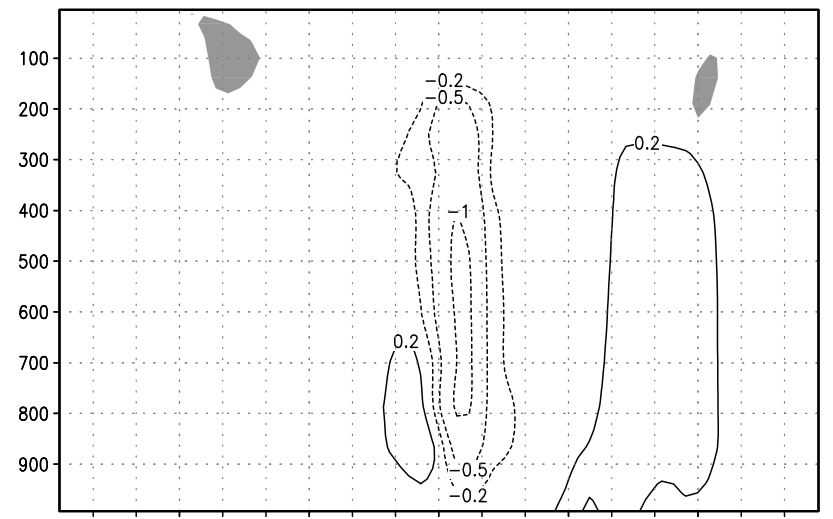

8OS TOS 6OS 5OS 4OS BOS 2OS IOS EQ ION 2ON 3ON 4ON 5ON 6ON 7ON 8ON JJA
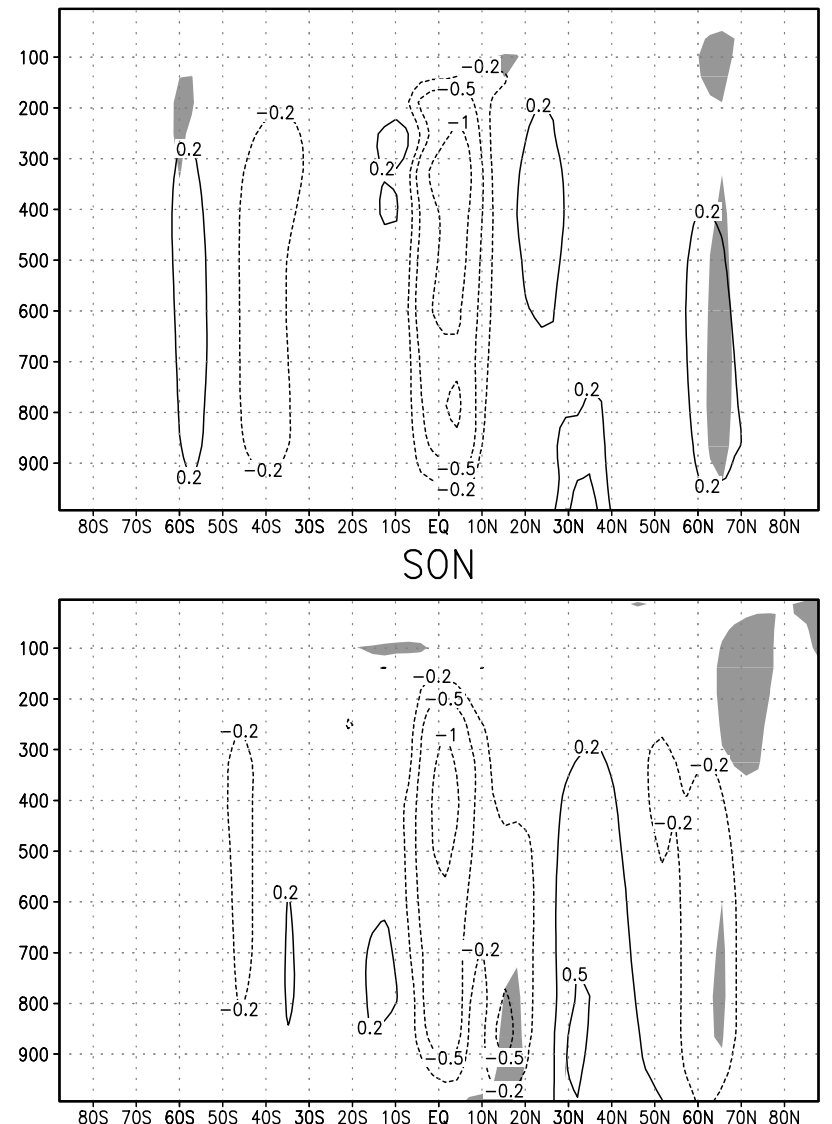
(c) $\mathrm{C}-\mathrm{N}-430$
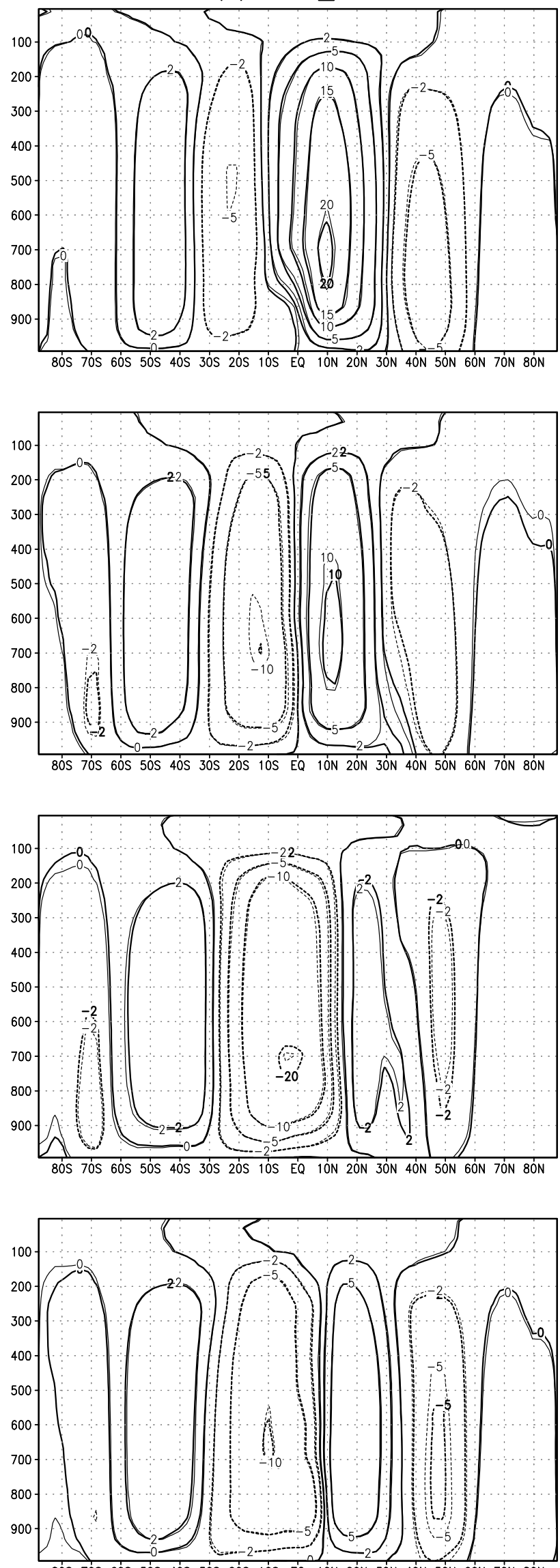

Difference in DJF

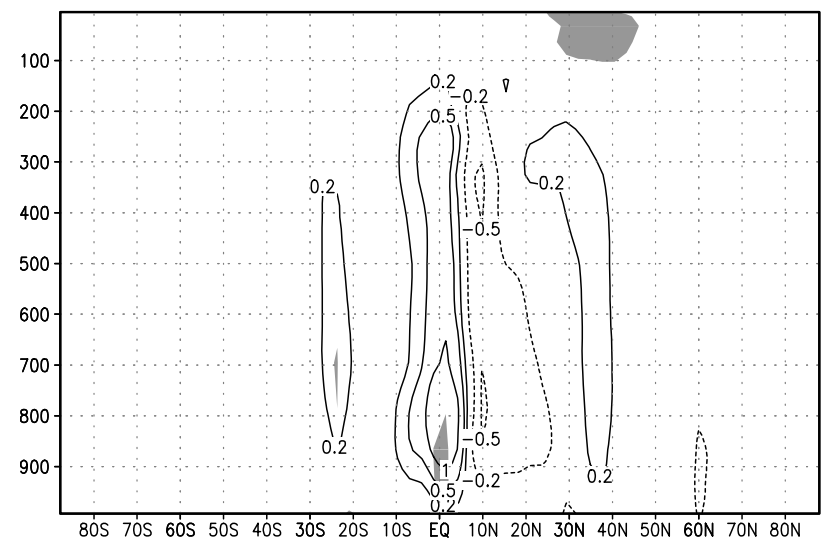

MAM

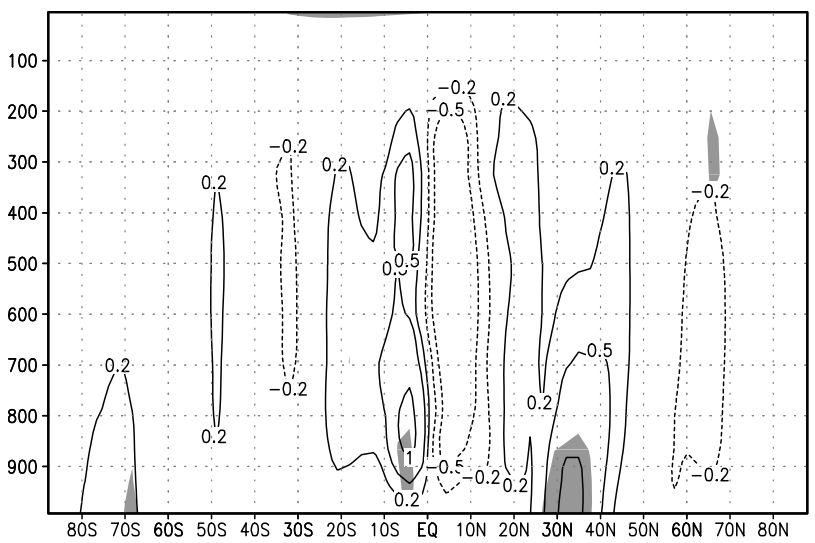

JJA
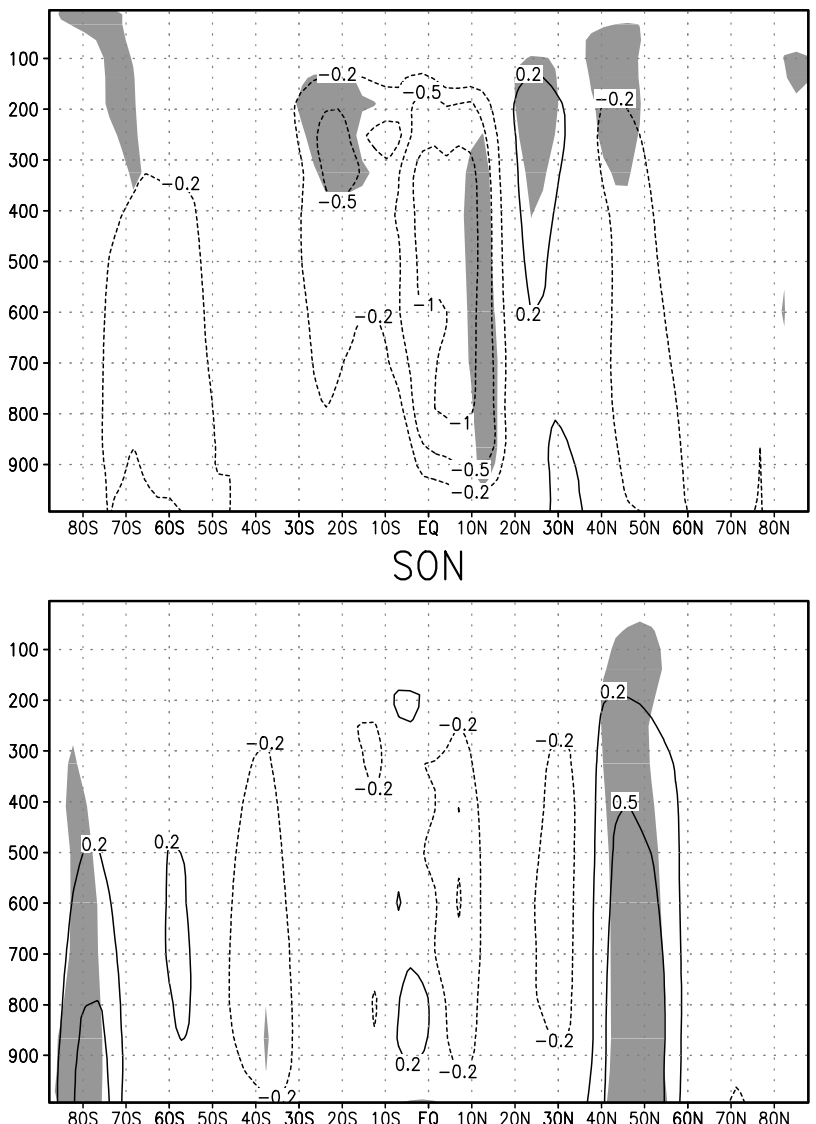

Fig. 10 (continued) 
$30^{\circ} \mathrm{N}$ at 280 ppmv. At 355 ppmv (Fig. 10b), the Hadley cell increases in intensity over both the equator and between 10 and $30^{\circ} \mathrm{N}$, and the change in the southern hemisphere branch is statistically significant. Finally, at 430 ppmv (Fig. 10c), the Hadley cell increases over the equator but decreases between 10 and $30^{\circ} \mathrm{N}$; the change is statistically significant only along the equator at low atmospheric levels. The lack of consistent changes in the Hadley cell in DJF is an indication that the interaction between $\mathrm{LCC}$ and $\mathrm{CO}_{2}$ changes, combined with model variability.

In contrast, we find some common changes to the atmospheric circulation due to LCC in the other seasons at the $3 \mathrm{CO}_{2}$ levels. The central maximum value of the Hadley cell decreases in MAM, and the equatorial side boundary of the Hadley cell moves away from the equator in both hemispheres. In JJA, the center maximum value increases and the boundary of the Hadley cell in the northern hemisphere moves northwards. The changes in the Hadley cell are larger and more significant at the lowest $\mathrm{CO}_{2}$ level (the maximum difference in the Hadley cell is $\sim 3.1 \times 10^{10} \mathrm{~kg} \mathrm{~s}^{-1}$ at 280 ppmv, and $\sim 1.2 \times 10^{10} \mathrm{~kg} \mathrm{~s}^{-1}$ at both 355 and 430 ppmv). In SON, the Ferrel cell becomes weaker in the northern hemisphere and the most statistically significant changes in this part of the atmospheric circulation occur at $430 \mathrm{ppmv}$.

The changes in the Hadley cell are consistent with changes in tropical precipitation, divergent outflow and in the $200 \mathrm{hPa}$ zonally averaged jet (reported previously in Zhao et al. 2001 for 355 ppmv). These all increase and move northwards at all $3 \mathrm{CO}_{2}$ levels (figures not shown). In JJA the Hadley cell also shows significant changes at both the smallest and largest $\mathrm{CO}_{2}$ concentrations.

We also investigated the impact of changes in $\mathrm{CO}_{2}$ on the large-scale circulation of the atmosphere. Under current land cover the $\mathrm{CO}_{2}$ impact on the zonally averaged meridional stream function (figure not shown) is statistically significant over a larger area than the impact of $\mathrm{CO}_{2}$ (under natural land cover) in all 4 seasons. In particular, the magnitude of the impact of increasing $\mathrm{CO}_{2}$ (from 280 to 430 ppmv) under current land cover is statistically significant over a much larger area in JJA than the equivalent change under natural land cover. Under current land cover, the change in $\mathrm{CO}_{2}$ from 280 to $430 \mathrm{ppmv}$ leads to a decrease in the Hadley cell of $1.0 \times 10^{10} \mathrm{~kg} \mathrm{~s}^{-1}$, and these changes are statistically significant between $10^{\circ} \mathrm{S}$ and $10^{\circ} \mathrm{N}$. Under natural land cover, the Hadley cell decreased in JJA by $0.5 \times 10^{10} \mathrm{~kg} \mathrm{~s}^{-1}$ and is not generally statistically significant. Under both land cover scenarios the northern boundary of the Hadley cell moves southwards.

Overall, these results imply that the impact of LCC on the large-scale circulation is non-linear and depends on interactions between the atmospheric circulation and $\mathrm{CO}_{2}$. The results also suggest that the impact of LCC and $\mathrm{CO}_{2}$ on the large-scale circulation patterns within the atmosphere are comparable in terms of size.

\section{DISCUSSION OF LCC EFFECTS}

The LCC imposed in these simulations caused regional thermal anomalies to develop via changes in net radiation, partitioning of surface fluxes and changes in hydrological characteristics. We have shown that these surface anomalies were quickly communicated vertically to the free atmosphere and then propagated to regions remote from direct LCC forcing. We have demonstrated that $\mathrm{LCC}$ resulted in changes in the mean meridional circulation at all $\mathrm{CO}_{2}$ levels, which is one explanation for climatic effects remote from regions directly affected by LCC. Other effects expected to be at work here include changes in stationary wave climatology (Chase et al. 1996), excitation of Rossby waves (Chase et al. 2000) and HadleyWalker circulation effects (Zhang et al. 1996), all of which will generally interact to bring about the overall response.

Four regions of common sensitivity and statistical significance in all $\mathrm{CO}_{2}$ scenarios were found remote from the areas of LCC: North Pacific, North America, northeast Asia and Indian Ocean (e.g. Figs. 8 \& 9). Hoskins \& Karoly (1981) showed that Rossby wave rays respond to tropical and mid-latitude thermal forcings along a great circle route propagating to the northeast (downstream from the source region, as well as poleward). However, mid-latitude forcings have a smaller response than those in the tropics. This might explain why the North Pacific, North America and northeast Asia, all of which are northeast of LCC perturbations, appear to be most sensitive to LCC. Additionally, LCC in India and China may induce remote changes over the Indian Ocean via Walker cell propagation zonally.

The initial atmospheric perturbation due to LCC is mostly independent of $\mathrm{CO}_{2}$ level. This is an indication that the differing response to $\mathrm{LCC}$ at different $\mathrm{CO}_{2}$ concentrations is a result of interactions between changes in the basic-state circulation due to $\mathrm{CO}_{2}$ and LCC changes. Peng et al. (1997) indicated that the basic-state is relatively important, especially when the atmosphere responds to heat anomalies at mid-latitudes. Our results suggest that we should pay attention to transient changes in $\mathrm{CO}_{2}$ levels when investigating the climatic impacts of LCC and vegetation feedback in future modeling (e.g. Betts et al. 1997, Levis et al. 1999).

LCC has a clear and statistically significant effect in summer (JJA), especially over Europe (although this 
may be the result of the pattern of LCC being substantially limited to the northern hemisphere). In part, this stronger local response in summer is likely to be due to greater available energy and therefore larger changes in sensible and latent heating following LCC. However, in addition, during summer in the mid-latitudes of the northern hemisphere, a moderately strong local temperature anomaly can develop following LCC. As the basic zonal winds lose intensity as summer is approached in the northern hemisphere, the effect of any anomaly induced by LCC is magnified as the atmospheric response changes from a strong basicstate advective state to a weak basic-state diabatic state. This encourages the anomaly to persist, which enhances the perturbation caused by LCC on the atmosphere (Webster 1982). Finally, the difference in vegetation parameters between current and natural land cover is the largest in JJA, which causes the largest temperature anomalies. This assists in the development of a relatively strong signal resulting from LCC in summer over Europe. With increasing $\mathrm{CO}_{2}$, warming might be expected to extend the seasonal time-scale of LCC impacts at mid- and high latitudes. In contrast, seasonal changes in vegetation parameters are small at low latitudes (e.g. India and south China) and the thermal forcings are within the region of easterly zonal winds, which allows a diabatic response in either season. Thus, we see clearly the local response to LCC in India and China in all 4 seasons.

\section{CONCLUSION}

The effect of initial perturbations in LCC can be traced to changes in the atmosphere which propagate away from the initial perturbation vertically and horizontally. LCC generates both local and remote effects which are statistically significant. The local responses are relatively common at $3 \mathrm{CO}_{2}$ levels, but vary in sign between locations and seasons, depending on the character of the initial land cover perturbation as well as local meteorological conditions. In contrast, the remote changes are more varied, depending on the $\mathrm{CO}_{2}$ level, but the effects of LCC do not disappear with increasing $\mathrm{CO}_{2}$ and may in some cases be amplified. Our results confirm that LCC can cause a permanent local heating anomaly source which is independent of $\mathrm{CO}_{2}$ concentrations.

Our results indicate that the correct land-surface distribution, and the evolution of this distribution in time, is likely to be important in attempts to simulate the regional-scale impacts of perturbations such as increasing $\mathrm{CO}_{2}$. Pitman \& Zhao (2000) have already shown that LCC, observed through the 20th century can have regional-scale effects which are comparable to the observed change in $\mathrm{CO}_{2}$. While the details of the results obtained by Brovkin et al. (1999) and Betts (1999) differ from our results in detail, all these studies have demonstrated that LCC appears to be significant in simulating climate and comparable in magnitude to the $\mathrm{CO}_{2}$ signal. The results presented here have demonstrated that the significance of LCC does not appear to be reduced at higher $\mathrm{CO}_{2}$ levels and suggest that LCC scenarios need to be included in transitory simulations of future climate. The impact of LCC on the large-scale circulation appears to be of similar order to the increase in $\mathrm{CO}_{2}$ from 280 to $430 \mathrm{ppmv}$ and has a larger impact on the Hadley circulation than the increase in $\mathrm{CO}_{2}$. It should be noted that this paper has only focussed on the structural changes induced by LCC, and $\mathrm{CO}_{2}$-induced biological feedbacks such as $\mathrm{CO}_{2}$ fertilization were not included. These may modify the conclusions reached in this paper, and hence one significant research priority is the inclusion of landsurface schemes into climate models which can simulate the evolution of the biology within increasing $\mathrm{CO}_{2}$. Overall, this should assist in attempts to detect and attribute warming observed during the 20th century (e.g. Santer et al. 1996). As a final caveat, the impacts of LCC reported here could be strongly dependent on the climate model (Raisanen 1999) or on the land-surface model used, and hence the role of LCC needs to be studied using different climate models.

Appendix 1. Two-way analysis of variance (ANOVA)

We select seasonal (such as DJF, MAM, JJA and SON) data for analysis. Suppose that $i$ different treatments were used, and that these were applied in random order to $i$ experimental units in $j$ blocks. $t$ is the years that experiments ran. We represent the resulting ijt outcomes of the experiment with random variables $X_{i j t}$ for $i=1, \ldots, 2, j=1$, $\ldots, 3$, and $t=1, \ldots, 15$, which we assume to be independent and normally distributed. If a completely randomized design is used, every treatment combination must be used more than once. If a blocked design is used, each treatment must be used within each block more than once. The test statistics used to test for block and treatment effects are identical to the fixed effects case, but the interpretation of the tests is quite different. There are also differences in the calculation of variance proportions. For more detail about ANOVA see von Storch \& Zwiers (1999), and for examples applied to GCM experiments see Zwiers (1996). Our ANOVA model form is

$$
X_{i j t}=\mu+a_{i}+b_{j}+c_{i j}+d_{i j t}
$$

where $i=1,2$ indicates the land cover type (natural or current), $j=1,2$ and 3 indicates the $3 \mathrm{CO}_{2}$ levels $(280,355$ and 
Appendix 1 (continued)

430 ppmv), and $t=1,2, \ldots, 15$ is time (in years). The terms in the model are as follows: $X_{i j t}$ is any seasonal mean quantity simulated in year $t$ of the run with land cover type $i$ and $\mathrm{CO}_{2}$ level $j_{;} \mu$ is the overall mean; $a_{i}$ is the effect of the $i$ th land cover type that is common to both levels of $\mathrm{CO}_{2 i} b_{j}$ is the effect of the $j$ th $\mathrm{CO}_{2}$ level that is common to both land cover types; $C_{i j}$ represents the interaction effect between land cover and $\mathrm{CO}_{2}$ level; and $d_{i j t}$ represents internal variability (variation between years and runs that is not accounted for by the other 3 terms). Here we only show the null hypothesis of land cover effects $H_{i}$ (i.e. whether $a_{1}=$ $\left.a_{2}=0\right) . H_{i}$ is tested by comparing

$$
F_{i}=\frac{S S S}{(i-1)} / \frac{S S I}{(i-1)(j-1)}
$$

with critical values from the $F$-distribution with $(i-1)$ and $(i-1)(j-1)$ degrees of freedom, where

$$
S S S=j \sum_{i=1}^{I}\left(X_{\text {ioo }}-X_{\text {ooo }}\right)^{2}
$$

is the between-simulations sum of squares that measures differences between the land cover impact of the ensemble members and

$$
S S I=\sum_{i=1}^{I} \sum_{j=1}^{J}\left(X_{i j o}-X_{i o o}-X_{o j o}+X_{o o o}\right)^{2}
$$

measures the internal or natural variation which remains when the other components have been accounted for. A 'circle' replaces a subscript when an average is taken over that index.
Acknowledgements. We gratefully thank the Australian National University Supercomputing Facility (especially Roger Brown, Ben Evans, Bob Gingold and Judy Jenkinson) for computing time and support. We thank Prof. Francis Zwiers and Dr Xiaogu Zheng for their help in statistical methods, Martin Claussen for a helpful review and an anonymous reviewer for other useful comments. M.Z. is supported by MUIPGRA scholarship. A.J.P. acknowledges support from the Australian Research Council small grants scheme.

\section{LITERATURE CITED}

Betts RA (1999) The impact of land use on the climate of the present day. In Ritchie H (ed) Research activities in atmospheric and oceanic modelling, CAS/JSC WGNE Report No. 28, WMO, Geneva, p 7.11-7.12

Betts RA, Cox PM, Lee SE, Woodward FI (1997) Contrasting physiological structural vegetation feedbacks in climate change simulations. Nature 387:796-799

Brovkin V, Ganopolski A, Claussen M, Kubatzki C, Petoukhov V (1999) Modelling climate response to historical land cover change. Global Ecol Biogeogr 8:509-517

Chase TN, Pielke RA, Kittel TGF, Nemani RR, Running SW (1996) Sensitivity of a general circulation model to global changes in leaf area index. J Geophys Res 101:7393-7408

Chase TN, Pielke RA, Kittel TGF, Nemani RR, Running SW (2000) Simulation impacts of historical land cover changes on global climate in northern winter. Clim Dyn 16:93-105

Chase TN, Pielke RA, Zhao M, Pitman AJ, Running SW, Nemani RR (2001) The relative climatic effects of landcover change and elevated carbon dioxide combined with aerosols: a comparison of model results and observations. $\mathrm{J}$ Geophys Res (in press)

Dickinson RE, Henderson-Sellers A, Kennedy PJ (1993) Biosphere-Atmosphere Transfer Scheme (BATS) version 1e as coupled to the NCAR Community Climate Model. NCAR Technical Note TN-387 + STR, August 1993, 72

Dirmeyer PA, Shukla J (1996) The effect on regional and global climate of expansion of the world's deserts. Q J R Meteorol Soc 122:451-482

Haxeltine A, Prentice IC (1996) BIOME3: An equilibrium terrestrial biosphere model based on ecophysiological constraints, resource availability, and competition among plant functional types. Global Biogeochem Cycles 10: 693-709
Hoskins BJ, Karoly DJ (1981) The steady linear response of a spherical atmosphere to thermal and orographic forcing. J Atmos Sci 38:1179-1196

Huntley B, Webb T III (1988) Vegetation history. Kluwer Academic Publishers, Dordrecht

Katz RW (1982) Statistical evaluation of climate experiments with general circulation models: a parametric time series modeling approach. J Atmos Sci 39:1446-1455

Kiehl JT, Bouville B, Hack J, Rasch P, Williamson D (1996) Description of the NCAR Community Climate Model (CCM3). NCAR Technical Note NCAR/TN-420 + STR Boulder, $\mathrm{CO}$

Levis S, Foley JA, Pollard D (1999) Potential high-latitude vegetation feedbacks on $\mathrm{CO}_{2}$-induced climate change. Geophys Res Lett 26:747-750

Meyers WB, Turner BL II (1994) Changes in land use and land cover: a global perspective. Cambridge University Press, Cambridge

Nicholson SE, Tucker CJ, Ba MB (1998) Desertification, drought and surface vegetation: an example from the West African Sahel. Bull Am Meteorol Soc 79:815-829

Peng S, Robinson WA, Hoerling MP (1997) The modeled atmospheric response to midlatitude SST anomalies and its dependence on background circulation states. J Clim 10:971-987

Pitman AJ, Zhao M (2000) The relative impact of observed change in land cover and carbon dioxide as simulated by a climate model. Geophys Res Lett 27:1267-1270

Polcher J, Laval K (1994) A statistical study of the regional impact of deforestation on climate in the LMD GCM. Clim Dyn 10:205-219

Raisanen J (1999) Internal variability as a cause of qualitative intermodel disagreement on anthropogenic climate changes. Theor Appl Climatol 64:1-13

Santer BD, Wigley TML, Barnett TP, Anyamba E (1995) Detection of climate change and attribution of cause. In: Meira Filho JT, Callender LG Harris BA Kattenberg N and Maskell K (eds) Climate change 1995: the science of climate change. Cambridge University Press, Cambridge, p 419-443

Thomas WL (1956) Man's role in change the face of the Earth. University of Chicago Press, Chicago

Turner BL II, Clark WC, Kates RW, Richards JF, Mathews JT, Meyer WB (1990) The earth as transformed by human action: global and regional changes in the biosphere over the past 300 years. Cambridge University Press, Cambridge 
Vitousek PM, Mooney HA, Lubchenco J, Melillo JM (1997) Human domination of Earth's ecosystems. Science 277: 494-499

von Storch H, Zwiers FW (1999) Statistical analysis in climate research. Cambridge University Press, Cambridge, p 171-191

Webster PJ (1982) Seasonality in the local and remote atmospheric response to sea temperature anomalies. J Atmos Sci 39:41-52

Xue Y (1997) Biosphere feedback on regional climate in tropical north Africa. Q J R Meteorol Soc 123:1483-1515

Editorial responsibility: Gerd Esser, Gießen, Germany
Zhang H, McGuffie K, Henderson-Sellers A (1996) Impacts of tropical deforestation. Part II: The role of large-scale dynamics. J Clim 9:2498-2521

Zhao M, Pitman AJ, Chase TN (2001) The impact of land cover change on the atmospheric circulation. Clim Dyn 17: 467-477

Zheng XG, Nakamura H, Renwick JA (2000) Potential predictability of seasonal means based on monthly time series of meteorological variables. J Clim 13:2591-2604

Zwiers FW (1996) Interannual variability and predictability in an ensemble of AMIP climate simulations conducted with the CCC GCM2. Clim Dyn 12:825-847

Submitted: July 3, 2000; Accepted: January 17, 2001 Proofs received from author(s): May 29, 2001 